九州大学学術情報リポジトリ

Kyushu University Institutional Repository

\title{
A monitoring technique for disbond area in CFRP bonded joints using embedded fiber Bragg grating sensors: development and experimental validation
}

Yashiro, Shigeki

Department of Mechanical Engineering, Shizuoka University

Wada, Jumpe i

Department of Mechanical Engineering, Shizuoka University

Sakaida, Yoshihisa

Department of Mechanical Engineering, Shizuoka University

http://hdl. handle. net/2324/4476136

出版情報：Structural Health Monitoring. 16 (2)，pp. 185-201，2017-03-01. SAGE Publications バージョン :

権利関係: (c) The Authors 
A monitoring technique for disbond area in CFRP bonded joints using embedded fiber Bragg grating sensors: development and experimental validation

Shigeki Yashiro ${ }^{1, *}$, Jumpei Wada ${ }^{1, a}$, Yoshihisa Sakaida ${ }^{1}$

${ }^{1}$ Department of Mechanical Engineering, Shizuoka University

${ }^{\text {a }}$ Current address: Nippi Corporation

*Corresponding author: yashiro.shigeki@shizuoka.ac.jp (S. Yashiro)

3-5-1 Johoku, Naka-ku, Hamamatsu 432-8561, Japan

Tel: +81-53-478-1026; Fax: +81-53-478-1026.

\section{Abstract}

This study evaluated fatigue-induced disbond areas in CFRP double-lap joints by using embedded fiber Bragg grating (FBG) sensors. When the disbond grew by cyclic loading, the embedded FBG sensors yielded reflection spectra having two peaks representing a step-like strain distribution generated by the disbond; the peak at the shorter wavelength corresponded to the unloaded disbond region. The ratio of the peak intensity at the shorter wavelength to that at the longer wavelength increased gradually with increasing disbond length. The relationship between the peak intensity ratio and the disbond length was analyzed by coupled structural-optical analysis and was validated by comparing analytical peak intensity ratio with experiment results. The disbond length was then estimated from the measured spectra based on this analytical calibration relationship, but the estimated disbond area exceeded that observed using the ultrasonic C-scan technique. Additional experiments 
including destructive observation of the adhesive suggested that an embedded FBG sensor could detect a moving disbond tip earlier than conventional nondestructive techniques.

Keywords: Structural health monitoring; Adhesively bonded joint; Composite materials; Debonding; Fatigue; Fiber Bragg gratings (FBGs); Full-spectral monitoring

\section{Introduction}

The number of components can be reduced in composite structures compared to conventional metal structures, but many joints will still exist. In composite structures, adhesively bonded joints are preferred over mechanical fastening because of their light weight. However, the bondline is frequently damaged due to cyclic loading or impact loading, and a disbond significantly degrades the safety of the joint due to deteriorated joint strength. Therefore, ensuring the soundness of bonded joints is a key requirement in composite structures. However, ensuring safety of bonded joints is an interesting challenge because of the difficulty in disassembling during routine maintenance, in addition to the difficulty in regular access for inspection in a real structure. Fiber-optic-based structural health monitoring $(\mathrm{SHM})$ is a promising candidate for this purpose.

A number of studies on SHM of composite bonded structures (including joints and repairs) have been reported in the literature. Fiber Bragg grating (FBG) sensors are promising for SHM because of their ability to accurately measure strain and temperature and to prepare multiple gage sections in a single optical fiber. Strain distribution in cracked joints has been measured by using multiplexed FBG sensors embedded near or in the bondline [1-8]. Li et al. [1,2] measured strain distribution in a GFRP T-joint by multiplexed FBGs and detected abnormal strain caused by disbond through a model- 
independent statistical method. Jiang et al. [3] embedded some FBG sensors in a CFRP lap plate of a steel-CFRP double-lap joint and found abrupt strain increase due to cracking of the adhesive. Bernasconi et al. [6] used a strain distribution measured by multiplexed FBG sensors to predict the disbond length based on an analyzed relationship between the position of minimum strain and the crack length. Bernasconi et al. [7] demonstrated good correlation between the disbond tip and the position of the embedded sensor, and pointed out that the sensitivity of an FBG to a disbond tip was comparable with ultrasonic testing. Schizas et al. [8] embedded wavelength multiplexed FBGs in a single-lap joint and monitored change in the non-homogeneous strain distribution caused by disbond extension.

Full-spectral response of FBGs is sensitive to strain distribution of the gage section, i.e., the spectrum is distorted by non-uniform strain [9-11], and this characteristic has been applied to damage detection of composite materials (e.g., Ref. [12]). Webb et al. [13,14] applied a dynamic full-spectrum FBG interrogator to a single FBG sensor embedded in the adhesive of a single-lap joint. They detected change in the full-spectral response caused by alternation of the strain field and indicated that structural nonlinear behavior due to disbond appear in the dynamic spectral response. A pre-chirped FBG sensor has a gradual change in the grating period, which yields a broad, flat reflection spectrum. The wavelength of the shape change has a one-to-one correspondence with the position in the gage section, and this feature has been applied to identify damage [15-17]. Palaniappan et al. [18,19] embedded a chirped FBG sensor near the bondline of a GFRP single-lap joint and validated the relationship between the disbond tip position and the wavelength of the shape change. They concluded that the accuracy of the estimated disbond tip was $2 \mathrm{~mm}$. Meanwhile, Murayama [20] developed a dynamic 
strain distribution sensing system based on optical frequency domain reflectometry and successfully measured strain distribution in a single-lap joint. Ning et al. [21] used this system to detect fatigueinduced disbond by directly measuring strain distribution of an embedded FBG sensor.

Damage of bonded repair panels has been monitored by FBG sensors [22-25]. Jones and his colleagues $[22,23]$ bonded a boron/epoxy composite patch onto a cracked aluminum plate and attached several FBG sensors to the patch. They detected extension of the crack by measuring unusual strain outputs caused by the distorted strain distribution, and also pointed out that the crack-induced nonuniform strain distribution caused deformation of the reflection spectrum. Sekine et al. [24] attached nine FBG sensors to a repair patch and estimated the disbond shape based on a mathematical optimization in which the center wavelength and the area of the reflection spectra were used in the objective function.

Bondlines in composite structural components have also been assessed using FBG sensors [26-33]. Kamath et al. [26] used embedded and/or attached FBGs to monitor strains of composite box structures, and detected abnormal strain responses near artificially introduced disbonds. Takeda et al. [27,28] detected nonlinear strain due to buckling by FBG sensors embedded at the skin/flange interface. They also concluded that a full-spectrum measurement (not just at the center wavelength) effectively monitored damage because the reflection spectrum was broadened by the damage. Prusty and Raju [29] specified the failure mode by acoustic emission measured by attached FBG sensors. They also measured damage-induced strain change using embedded FBG sensors. Tserpes et al. [30,31] measured the strain generated by local buckling of a skin-stiffener panel using FBG sensors embedded in the panel. Damage detection of composite stiffened panels has been performed through dynamic 
response of structures. Takeda et al. [32] developed an ultrasonic signal collection system using FBGs and monitored disbond of a stringer by wavelet transform of the collected signals. Loutas et al. [33] recognized the presence of damage and its position by signal processing and pattern recognition techniques for ultrasonic signals collected by attached FBGs.

In many conventional studies on FBG-based SHM of bonded composite structures, the strains at several gage sections were measured from the center wavelength, and the disbond tip (or the position of damage) was detected by the position of the gage section that indicated a drastic strain change. In this approach, the FBG sensor was just a substitute for a foil strain gage, and the resolution of the disbond tip would be comparable to the gage length of the FBG sensor. However, the reflection spectrum of an FBG sensor responds sensitively to a non-uniform strain distribution [9-12,34], and the full-spectral monitoring will provide better resolution than a conventional multi-point strain monitoring approach $[18,19]$.

This study thus investigates the nondestructive detection and evaluation of disbond growth in CFRP adhesively bonded joints based on the change in the spectrum shape of FBG sensors embedded near the bondline. More specifically, we aim to estimate the disbond area by using several embedded FBG sensors. This study is organized as follows. Section 2 summarizes fatigue tests of CFRP double-lap joints with embedded FBG sensors. Section 3 proposes an approach for estimating the disbond area and applies it to the experiment results. The cause of the difference between the estimate and the observation by conventional NDTs is investigated, and the characteristic of the present approach is discussed. 


\section{Experiment}

\subsection{Procedure}

Figure 1 presents the CFRP double-lap joint specimen with three embedded FBG sensors. Quasiisotropic laminates (T700S/\#2592, Toray Industries) were manufactured using a vacuum hot-pressing machine; the stacking sequence was $[0 / 45 / 90 /-45]$ s. Three laminates were then bonded by epoxidebased film adhesive (FVE9F-0226A, JX Nippon Oil \& Energy) under $2.06 \mathrm{MPa}$ pressure and $130^{\circ} \mathrm{C}$ temperature for one hour. This film adhesive was composed of polyester non-woven fabric and modified epoxy resin, and the resin weight ratio was $85 \%$. Total areal weight of the adhesive was 167 $\mathrm{g} / \mathrm{m}^{2}$. Finally, GFRP tabs were attached to the joint-ends to avoid grip failure.

Figure 1c depicts a cross-section image of the lap-section. Three polyimide-coated FBG sensors (NTT Advanced Technology) were embedded in the top $0^{\circ}$ ply of a laminate in its fiber direction. Their outer diameter was $150 \mu \mathrm{m}$, and the gage length was $25 \mathrm{~mm}$. The lap-plate with FBG sensors was attached to the center plate so that the FBG gage sections coincided with the bonded section and contacted the bondline. A pre-disbond $2 \mathrm{~mm}$ long was introduced to the bondline near the FBG sensors by inserting a polytetrafluoroethylene (PTFE) sheet $(0.05 \mathrm{~mm}$ thick). The PTFE sheet was removed after the adhesive was cured. This pre-disbond ensured crack growth at the bondline adjacent to the FBG sensors.

The double-lap joint specimen with FBG sensors was subjected to cyclic loading. The maximum stress was $40 \%$ of its static strength, measured in advance, and the stress ratio was 0.1 . The loading pattern was sinusoidal with $5 \mathrm{~Hz}$ cyclic frequency. The static strength $(28.1 \mathrm{MPa})$ was defined as the breaking load of tensile tests divided by the bond area, because the bondline with the initial defect 
always broke. The fatigue test was interrupted at the mean stress condition after every 1000 cycles, and reflection spectra of the three FBG sensors were obtained under the mean stress condition. Broadband light from an ASE light source (AQ4315A, Ando Electric) was injected into the FBG sensor via a circulator and an optical switch (AQ8201-414 and AQ8203, Ando Electric). Narrowband reflected light was measured by an optical spectrum analyzer (AQ6319, Ando Electric). The specimen was then unloaded, and was inspected by ultrasonic C-scan technique. An ultrasonic C-scan inspection system (TT-UTCS01, Tsukuba Technology) with an immersion probe (B3.5K10IPF30, Japan Probe) was used, and the scanning interval was $0.2 \mathrm{~mm}$. The center frequency of the ultrasonic probe was 3.5 $\mathrm{MHz}$, and the point-focus distance was $30 \mathrm{~mm}$.

\subsection{Experiment results}

Figure 2 depicts the ultrasonic C-scan images. Despite the existence of the pre-disbond, a welldefined disbond could not be observed before the test, probably because of the detectability. A disbond was detected at $N=2000$ cycles and extended from the pre-disbond as the number of cycles increased. The specimen broke after $N=10000$ cycles, although intact region was still observed.

Figure 3 presents the change in the reflection spectrum of the embedded FBG sensors measured at the mean stress condition. The peak wavelength of the reflection spectrum is proportional to the fiber axial strain, since it can be expressed as $\lambda=2 n \Lambda ; n$ is the effective refractive index of the fundamental mode of the optical fiber, and $\Lambda$ is the grating period. In all three sensors having an initial narrow peak at $1550.5 \mathrm{~nm}$, a new narrow peak appeared at a shorter wavelength $(1549 \mathrm{~nm})$ after 1000 cycles. The wavelength of this new peak coincided with that of the initial narrowband spectrum without loading 
because the disbonded lap-plate could not carry the tensile load. The intensity of the new peak increased with increasing disbond length, while that of the original peak decreased. Overall intensity of FBG \#2 decreased at 6000 cycles because the optical fiber broke partially at the egress from the lap plate. However, the magnitude of the optical intensity, per se, was not important in this study, since it is the intensity ratio of the two peaks which has close relation to the disbond length, as will be described in the following section.

\section{Identification of the disbond area}

First, the peak intensity ratio is introduced to quantitatively evaluate the distorted spectrum shape (Fig. 4), and an approach for estimating the disbond area (Fig. 5) is presented. The estimation is based on the relationship between the peak intensity ratio and the disbond length, and this relationship is derived analytically by the finite-element structural analysis (Fig. 6) and the optical analysis for FBGs (Fig. 7). The disbond area is then estimated from the measured spectra depicted in Fig. 3.

In order to verify this approach, the strain distribution (Fig. 8) and the reflection spectrum (Fig. 9) are predicted with considering the estimated disbond. The estimation shows good agreement with the measurement regarding the peak intensity ratio (Fig. 4), but the estimated disbond area differs from the observation by conventional NDTs (Fig. 10). Finally, the cause of the difference between the estimate and the observation will be discussed.

\subsection{Modeling}

Let us first define the peak intensity ratio $\left(I_{2} / I_{1}\right)[35]$ to quantitatively evaluate the change in the 
spectrum shape, where $I_{1}\left(I_{2}\right)$ is the reflectivity of the original (new) peak at the longer (shorter) wavelength. Figure 4 plots the peak intensity ratio of the experiment result (Fig. 3) against the number of cycles. The peak intensity ratio increased monotonically with increasing the number of cycles and the disbond length. Thus, we employed this ratio as the parameter for estimating disbond length. Figure 5 presents the procedure for estimating the disbond area using reflection spectra as well as a verification procedure. The disbond length along an FBG sensor was obtained from the peak intensity ratio in the experiment, based on a calibration curve (described later). The disbond lengths at the three sensor positions were identified from the measured spectra, and the disbond area was estimated by connecting the three positions of crack tips using a quadratic curve.

The relationship between the peak intensity ratio and the disbond length, i.e., the calibration curve, was defined by a combined analysis of the joint structure and the light propagation. The strain distribution of the joint was first predicted by commercial finite-element software, ANSYS version 15 . Figure 6 depicts the finite-element model for the double-lap joint specimen. The dimensions of the model were the same as for the experiment, and three laminates were represented by four-node layered shell elements, in which the quasi-isotropic lamination was taken into account. Since no damage was observed in the three CFRP plates, layered shell elements were sufficient for modeling the laminates. These plates were bonded by the coupling feature of ANSYS, and a disbond was expressed by removing the coupling in the damaged area. The adhesive layer was $0.05 \mathrm{~mm}$ thick. There were 30753 nodes and 30000 elements. The left end of the model was fixed in the $x$-direction, and the mean stress of the fatigue test was applied to the right end. A temperature change in the fabrication process $(\Delta T=$ $-110^{\circ} \mathrm{C}$ ) was also applied to the model to allow it to consider the thermal residual stresses. The material 
properties used in the structural analysis are listed in Table 1. The grating period and the effective refractive index of the FBG sensor were calculated taking into account the strain distribution obtained in the structural analysis [34]. The reflection spectrum was then calculated based on the mode-coupling equations for FBG sensors using the transfer matrix method $[34,37,38]$. The parameters used in the optical analysis are listed in Table 2.

Strain field was analyzed for models having a rectangular disbond area. Figure 7 a plots the strain distribution of the FBG sensor in the case of $12 \mathrm{~mm}$ disbond length; the sensor strain was assumed to be equal to the strain $\varepsilon_{x x}$ at the center of the width of the lap plate. Approximately step-like strain distribution was observed. Small thermal residual strain in the fabrication process appeared in the disbond region, and almost constant strain was generated in the intact region. The reflection spectrum obtained from this strain distribution (Fig. 7b) had two narrow peaks, corresponding to the step-like strain distribution. Although the length of the disbond area was nearly equal to that of the bonded area, the peak in the shorter wavelength had wide bandwidth and low intensity, since the strain in the disbond area gradually changed. We prepared several models having a rectangular disbond area with different length $(0-24 \mathrm{~mm})$, and analyzed the strain distribution and corresponding reflection spectrum. Figure 7c plots the numerically obtained relationship between the peak intensity ratio and the disbond length. The peak intensity ratio $\log _{10}\left(I_{2} / I_{1}\right)$ increased gradually with increasing disbond length, and this relationship was fitted empirically by a polynomial expression as

$$
\log _{10} \frac{I_{2}}{I_{1}}=0.0013 X^{3}-0.0477 X^{2}+0.6428 X-3.3511
$$


where $X$ denotes the disbond length. The disbond length can be estimated from the measured reflection spectrum by solving this equation. Naturally, this empirical equation is available to the specific case of this study. However, the peak intensity ratio can be defined in a general case, if the step-like strain distribution is achieved. The substitute of Eq. (1) will be obtained by the same procedure, i.e., the finite-element analysis for the geometry considered and the following optical analysis.

\subsection{Estimated results}

Disbond lengths along the three sensor lines were estimated from the measured reflection spectra (Fig. 3) by using Eq. (1), and the disbond area was determined by connecting the three disbond tips with a quadratic curve. This disbond area was represented in the finite-element model, and strain field was evaluated. Figure 8 presents a contour plot of the longitudinal strain $\varepsilon_{x x}$ considering the disbond area determined by the reflection spectra measured at $N=2000$ and 8000 . The strain in the disbond area was almost zero, and a step-like strain distribution appeared in the longitudinal $(x)$ direction. Figure 9 presents the analyzed reflection spectra of the three FBG sensors considering the estimated disbond area. The spectrum had two peaks. The original peak was at a longer wavelength (1550.5 nm), reflecting the constant tensile strain in the intact region, and a new peak appeared after 2000 cycles at a shorter wavelength $(1549 \mathrm{~nm})$, reflecting the unloaded disbond area.

Figure 4 compares the peak intensity ratio of the estimation (Fig. 9) with the experiments (Fig. 3). The estimated disbond area and corresponding strain distribution were based on the completelyanalytical relationship between the peak intensity ratio and the disbond length. Nevertheless, the estimated peak intensity ratio increased monotonically with increasing the cycles, and this trend agreed 
well with the measured results. This agreement indicates the validity of this approach to predicting the disbond area using the peak intensity ratio, as well as the analytical relationship between the peak intensity ratio and the disbond length.

Figure 10 compares the estimated disbond lengths at the three sensor positions with the observations using the ultrasonic C-scan technique (Fig. 2). This study assumed the line of the median value of the amplitude (i.e., the band of white color tone) as the disbond tip. The thickness of the white band would be an error, and the error range is presented by error bars in Fig. 10. The estimate exceeded the disbond area detected by $\mathrm{C}$-scan images after 2000 cycles, and the difference became greater with increasing cycles. The possibility regarding the difference between the estimate and the observation made by the ultrasonic C-scan technique involves the difference in sensing direction. FBG sensors generally have very high sensitivity to strain in their longitudinal direction, while the ultrasonic C-scan technique detects the interface with a clear difference in the acoustic impedance in the through-thickness direction. In the present disbond problem, the FBG sensors had advantage over the ultrasonic C-scan technique because the step-like strain distribution provided two distinct, narrow peaks in the reflection spectrum and because crack closure makes it difficult to detect crack tips by ultrasonic testing.

In order to investigate the difference in the disbond results between FBG sensors and conventional NDTs, additional experiments were performed, as described in the next section.

\subsection{Discussion}

An additional experiment was conducted to clarify the cause of the discrepancy observed in Fig. 10. The fatigue test was interrupted at 5000 cycles, and the joint specimen was inspected by conventional 
NDTs. The contrast agent for soft X-ray radiography (zinc iodide) was applied to the specimen edges at the mean stress condition, and the specimen was held at that state for a few minutes. The specimen was then unloaded and inspected by a soft X-ray inspection apparatus (M-100, Softex) with a digital X-ray sensor (NAOMI-NX 016H, RF Co.,Ltd.). The specimen was also evaluated by the ultrasonic Cscan technique. Figure 11 depicts a typical ultrasonic C-scan image and soft X-ray photograph of the results, along with a microphotograph of the manually-broken specimen, in which the infiltrated mark of the contrast agent for soft X-ray radiography was observed. The disbond area detected by the ultrasonic C-scan technique and soft X-ray radiography was smaller than the damaged area of destructive observation, which may include a crack-tip process zone in addition to the well-defined disbond. This experiment suggested the difficulty of conventional NDTs to detect a disbond with an infinitesimal crack opening distance like a kissing bond or a crack-tip process zone.

An embedded FBG sensor was then used to detect a moving disbond. An FBG sensor whose gage section was positioned at the end of an optical fiber was embedded, and the end of the gage section (i.e., the end of the optical fiber) was positioned $5 \mathrm{~mm}$ away from the edge of the bonded section. Here, an FBG sensor was cut in its gage section to clarify the end of the gage section. The fatigue test was interrupted just after the reflection spectrum was deformed, and the damage was observed using the ultrasonic C-scan technique and soft X-ray radiography. The change in the spectrum shape indicated that the FBG sensor had detected a change in the strain distribution.

Figure 12 presents the deformed reflection spectrum along with the NDT results. The initially narrow reflection spectrum became broad when the cyclic loading was interrupted (Fig. 12a bold line), and this indicates that condition of the disbond was altered. The disbond length from the ultrasonic C- 
scan technique (Fig. 12b) and soft X-ray radiography (Fig. 12c) was obviously smaller than $5 \mathrm{~mm}$. This additional experiment demonstrated that the embedded FBG sensor detected a moving disbond tip, which would be extension of the damage process zone, earlier than the conventional NDTs. Since the adhesive used in this study contained non-woven fabric, fiber-bridging zone would be generated ahead of the disbond tip. It is noted that, if in situ nondestructive evaluation is performed under the loaded condition, the results may be much closer.

The step-like strain distribution in the sensor longitudinal direction ensured the high detectability of the disbond tip with the FBG sensors. Thus, the proposed approach for estimating the disbond area has two advantages over conventional NDTs, continuous damage monitoring ability and disbond evaluation on the side of prudence.

Detectability of the disbond tip of the present method will be similar to that of the pre-chirped FBG sensor $(<2 \mathrm{~mm}[18,19,41])$, because both methods used full spectral signals distorted by non-uniform strain. Various fiber-optic based techniques have been used for detection and monitoring of disbond growth in lap joints. When multiplexed FBG sensors were used as a set of strain gages, the resolution of the disbond detection was approximately the gage length of each FBG (typically a few mm) without sophisticated estimation methods. Ultrasonic pitch-catch testing has been performed by using fiberoptic based techniques for wave reception, and the disbond growth was monitored by signal processing. FBG sensors [32,39] and a fiber-optic Doppler sensor [40] were employed for this purpose. Detectability by ultrasonic testing is comparable to the wavelength of ultrasonic waves used, independently of the reception method. Recently, Sulejmani et al. [42] proposed an FBG sensor written 
in a micro-structured optical fiber and measured shear strain by stress-induced birefringence. Although this sensor was a point sensor, its detection accuracy of disbond tip was $100 \mu \mathrm{m}$.

\section{Conclusions}

This study developed and verified a simple diagnostic method of the disbond area in a CFRP doublelap joint based on a change in the spectrum shapes of FBG sensors embedded near the bondline. The FBG sensors experienced a step-like strain distribution that represented the intact load-carrying section and the disbonded stress-free section. The reflection spectrum then exhibited a characteristic shape with two peaks. The reflection spectrum was then predicted with considering a rectangular disbond by a finite-element structural analysis and an optical analysis, and the relationship between the intensity ratio of the two peaks and the disbond length was obtained analytically. Based on the empirical fit of this analytical calibration curve, the disbond area was determined from the measured peak intensity ratio of three FBG sensors embedded in different lines of a joint. The conclusions are summarized below.

1. The characteristic two-peak reflection spectra were measured in all embedded FBG sensors, and the intensity ratio of the new peak to the original peak increased monotonically with increasing disbond length, because the intensity of the new peak corresponded to the disbond length.

2. The reflection spectrum was analyzed taking into account the estimated disbond area, and the increasing trend of the peak intensity ratio of the estimation agreed with the experiment results. This confirms the simple approach for estimating the disbond area.

The use of full spectral signals enabled us to specify the strain field within the gage section. Since 
the two distinct peaks in the reflection spectrum had one-to-one correspondence to the step-like strain distribution generated by the disbond, the peak intensity ratio can be used to identify the disbond length. Additional experiments suggested that the high sensitivity of FBGs to non-uniform strain distribution offered capability of early assessment of a moving disbond tip.

This study monitored and evaluated a known disbond under a simple condition. Quantitative detection and evaluation of the disbond in general cases will need further development.

\section{References}

[1] Li HCH, Herszberg I, Mouritz AP. Automated characterization of structural disbonds by statistical examination of bond-line strain distribution. Struct Health Monit 2006; 5(1):83-94.

[2] Li HCH, Herszberg I, Davis CE, Mouritz AP, Galea SC. Health monitoring of marine composite structural joints using fibre optic sensors. Compos Struct 2006; 75(1-4):321-327.

[3] Jiang G, Dawood M, Peters K, Rizkalla S. Global and local fiber optic sensors for health monitoring of civil engineering infrastructure retrofit with FRP materials. Struct Health Monit 2010; 9(4):309-322.

[4] Silva-Muñoz RA, Lopez-Anido RA. Structural health monitoring of marine composite structural joints using embedded fiber Bragg grating strain sensors. Compos Struct 2009; 89(2):224-234.

[5] Canal LP, Sarfaraz R, Violakis G, Botsis J, Michaud V, Limberger HG. Monitoring strain gradients in adhesive composite joints by embedded fiber Bragg grating sensors. Compos Struct 2014; 112:241-247.

[6] Bernasconi A, Kharshiduzzaman M, Anodio LF, Bordegoni M, Re GM, Braghin F, Comolli L. 
Development of a monitoring system for crack growth in bonded single-lap joints based on the strain field and visualization by augmented reality. J Adhesion 2014; 90(5-6):496-510.

[7] Bernasconia A, Carbonia M, Comolli L. Monitoring of fatigue crack growth in composite adhesively bonded joints using Fiber Bragg Gratings. Procedia Engineering 2011; 10:207-212.

[8] Schizas C, Stutz S, Botsis J, Coric D. Monitoring of non-homogeneous strains in composites with embedded wavelength multiplexed fiber Bragg gratings: A methodological study. Compos Struct 2012; 94(3):987-994.

[9] Peters K, Pattis P, Botsis J, Giaccari P. Experimental verification of response of embedded optical fiber Bragg grating sensors in non-homogeneous strain fields. Opt Laser Eng 2000; 33(2):107119.

[10]Peters K, Studer M, Botsis J, Iocco A, Limberger H, Salathé R. Embedded optical fiber Bragg grating sensor in a nonuniform strain field: measurements and simulations. Exp Mech 2001;41(1):19-28.

[11]Botsis J, Humbert L, Colpo F, Giaccari P. Embedded fiber Bragg grating sensor for internal strain measurements in polymeric materials. Opt Laser Eng 2005;43(3-5):491-510.

[12] Okabe Y, Yashiro S, Kosaka T, Takeda N. Detection of transverse cracks in CFRP composites using embedded fiber Bragg grating sensors. Smart Mater Struct 2000;9(6):832-838.

[13] Webb S, Shin P, Peters K, Zikry MA, Stan N, Chadderdon S, Selfridge R, Schultz S. Characterization of fatigue damage in adhesively bonded lap joints through dynamic, fullspectral interrogation of fiber Bragg grating sensors: 1. Experiments. Smart Mater Struct 2014; 23(2):025016. 
[14] Webb S, Shin P, Peters K, Zikry MA, Stan N, Chadderdon S, Selfridge R, Schultz S. Characterization of fatigue damage in adhesively bonded lap joints through dynamic, fullspectral interrogation of fiber Bragg grating sensors: 2. Simulations. Smart Mater Struct 2014; 23(2):025017

[15] Okabe Y, Tsuji R, Takeda N. Application of chirped fiber Bragg grating sensors for identification of crack locations in composites. Compos Part A 2004; 35(1):59-65.

[16] Yashiro S, Okabe T, Takeda N. Damage identification in a holed CFRP laminate using a chirped fiber Bragg grating sensor. Compos Sci Technol 2007; 67(2):286-295.

[17] Takeda S, Okabe Y, Takeda N. Monitoring of delamination growth in CFRP laminates using chirped FBG sensors. J Intell Mater Syst Struct 2008; 19(4):437-444.

[18] Palaniappan J, Wang H, Ogin SL, Thorne AM, Reed GT, Crocombe AD, Rech Y, Tjin SC. Changes in the reflected spectra of embedded chirped fibre Bragg gratings used to monitor disbonding in bonded composite joints. Compos Sci Technol 2007; 67(13):2847-2853.

[19]Palaniappan J, Ogin SL, Thorne AM, Reed GT, Crocombe AD, Capell TF, Tjin SC, Mohanty L. Disbond growth detection in composite-composite single-lap joints using chirped FBG sensors. Compos Sci Technol 2008; 68(12):2410-2417.

[20]Murayama H, Kageyama K, Uzawa K, Ohara K, Igawa H. Strain monitoring of a single-lap joint with embedded fiber-optic distributed sensors. Struct Health Monit 2012; 11(3):325-344.

[21]Ning X, Murayama H, Kageyama K, Wada D, Kanai M, Ohsawa I, Igawa H. Dynamic strain distribution measurement and crack detection of an adhesive-bonded single-lap joint under cyclic loading using embedded FBG. Smart Mater Struct 2014; 23(10):105011. 
[22] McKenzie I, Jones R, Marshall IH, Galea S. Optical fibre sensors for health monitoring of bonded repair systems. Compos Struct 2000; 50(4):405-416.

[23] Jones R, Galea S. Health monitoring of composite repairs and joints using optical fibres. Compos Struct 2002; 58(3):397-403.

[24] Sekine H, Fujimoto SE, Okabe T, Takeda N, Yokobori T. Structural health monitoring of cracked aircraft panels repaired with bonded patches using fiber Bragg grating sensors. Appl Compos Mater 2006; 13(2):87-98.

[25] Papantoniou A, Rigas G, Alexopoulos ND. Assessment of the strain monitoring reliability of fiber Bragg grating sensor (FBGs) in advanced composite structures. Compos Struct 2011; 93(9):21632172.

[26]Kamath GM, Sundaram R, Gupta N, Rao MS. Damage studies in composite structures for structural health monitoring using strain sensors. Struct Health Monit 2010; 9(6):497-512.

[27] Takeda S, Aoki Y, Ishikawa T, Takeda N, Kikukawa H. Structural health monitoring of composite wing structure during durability test. Compos Struct 2007; 79(1):133-139.

[28] Takeda S, Aoki Y, Nagao Y. Damage monitoring of CFRP stiffened panels under compressive load using FBG sensors. Compos Struct 2012; 94(3):813-819.

[29]Prusty BG, Raju. Failure investigation of top-hat composite stiffened panels. Ships Offshore Struct 2014; 9(2):186-198.

[30] Tserpes KI, Karachalios V, Giannopoulos I, Prentzias V, Ruzek R. Strain and damage monitoring in CFRP fuselage panels using fiber Bragg grating sensors. Part I: Design, manufacturing and impact testing. Compos Struct 2014; 107:726-736. 
[31]Ruzek R, Kudrna P, Kadlec M, Karachalios V, Tserpes KI. Strain and damage monitoring in CFRP fuselage panels using fiber Bragg grating sensors. Part II: Mechanical testing and validation. Compos Struct 2014; 107:737-744.

[32] Takeda N, Okabe Y, Mizutani T. Damage detection in composites using optical fibre sensors. Proc. IMechE Part G: J Aerosp Eng 2007; 221(4):497-508.

[33]Loutas TH, Panopoulou A, Roulias D, Kostopoulos V. Intelligent health monitoring of aerospace composite structures based on dynamic strain measurements. Expert Syst Appl 2012; 39(9):84128422

[34] Yashiro S, Takeda N, Okabe T, Sekine H. A new approach to predicting multiple damage states in composite laminates with embedded FBG sensors. Compos Sci Technol 2005; 65(3-4):659-667.

[35] Takeda S, Okabe Y, Yamamoto T, Takeda N. Detection of edge delamination in CFRP laminates under cyclic loading using small-diameter FBG sensor. Compos Sci Technol 2003; 63(13):18851894.

[36] Yashiro S, Ono R, Ogi K, Sakaida Y. Prediction of shear-cutting process of CFRP cross-ply laminates using smoothed particle hydrodynamics. Proceedings of the 16th US-Japan Conference on Composite Materials, San Diego, 8-10 September 2014, paper No. 747.

[37]Huang S, LeBlanc M, Ohn MM, Measures RM. Bragg intragrating structural sensing. Appl Opt 1995; 34(22):5003-5009.

[38] Prabhugoud M, Peters K. Modified transfer matrix formulation for Bragg grating strain sensors. J Lightwave Technol 2004; 22(10):2302-2309. 
[39] Okabe Y, Kuwahara J, Natori K, Takeda N, Ogisu T, Kojima S, Komatsuzaki S. Evaluation of debonding progress in composite bonded structures using ultrasonic waves received in fiber Bragg grating sensors. Smart Mater Struct 2007; 16:1370-1378.

[40]Li F, Murayama H, Kageyama K, Meng Gg, Ohsawa I, Shirai T. A fiber optic Doppler sensor and its application in debonding detection for composite structures. Sensors 2010; 10:5975-5993.

[41]Palaniappan J, Ogin SL, Capell TF, Thorne AM, Reed GT, Crocombe AD, Tjin SC, Mohanty L. Reflected spectra predictions for chirped fibre bragg gratings used for disbond detection in composite/composite joints. In: Proceedings of ICCM-16 Conference. Kyoto, July, 2007. No. MoBA1-02.

[42] Sulejmani S, Sonnenfeld C, Geernaert T, Luyckx G, Mergo P, Urbanczyk W, Chah K, Thienpont H, Berghmans F. Disbond monitoring in adhesive joints using shear stress optical fiber sensors. Smart Mater Struct 2014; 23:075006. 


\section{Figure captions}

Figure 1 CFRP double-lap joint specimen with three embedded FBG sensors. (a) Dimensions. (b) Overview of the specimen. (c) Cross-section of the lap-section.

Figure 2 Ultrasonic C-scan images observing extension of the disbond.

Figure 3 Measured reflection spectra of embedded FBG sensors. A new peak at a shorter wavelength appeared and grew as the number of cycles increased.

Figure 4 Comparison of the peak intensity ratio between the experiment and the estimate.

Figure 5 Estimation procedure for disbond area using the reflection spectrum and its verification procedure.

Figure 6 Finite-element model of the double-lap joint specimen with disbond.

Figure 7 Analytical results with considering rectangular disbond area. (a) Strain distribution and (b) reflection spectrum of the FBG with $12 \mathrm{~mm}$ disbond length; (c) analytical relationship between the peak intensity ratio and the disbond length.

Figure 8 Longitudinal strain $\varepsilon_{x x}$ distribution considering the estimated disbond area.

Figure 9 Analyzed reflection spectra of FBG sensors considering the estimated disbond area.

Figure 10 Comparison of the disbond length evaluated by the ultrasonic $\mathrm{C}$-scan technique with the one estimated from the measured reflection spectra. Error bars represent the error range caused by the thickness of the band of white color tone in the C-scan images.

Figure 11 Typical results of nondestructive inspections after 5000 cycles, along with a photograph of the manually-broken specimen.

Figure 12 Change in the spectrum shape due to disbond extension, and nondestructive inspections of the tested specimen at 300 cycles. 
Table 1 Material properties of CFRP unidirectional laminates [36].

Longitudinal Young's modulus (GPa)

Transverse Young's modulus (GPa)

In-plane shear modulus (GPa)

Out-of-plane shear modulus (GPa)

In-plane Poisson's ratio

Out-of-plane Poisson's ratio

Longitudinal thermal expansion coefficient $\left(\mathrm{K}^{-1}\right)$

Transverse thermal expansion coefficient $\left(\mathrm{K}^{-1}\right)$
139

9.85

5.25

3.8

0.25

0.38

0

$30 \times 10^{-6}$ 
Table 2 Optical properties of FBG sensors used in the optical analysis.

Gage length (mm)

Initial center wavelength (nm)

Effective refractive index

Strain-optic coefficient $p_{11}$

Strain-optic coefficient $p_{12}$

Poisson's ratio of the optical fiber
25.0

1549.189

1.46

0.113

0.252

0.16 
(a)

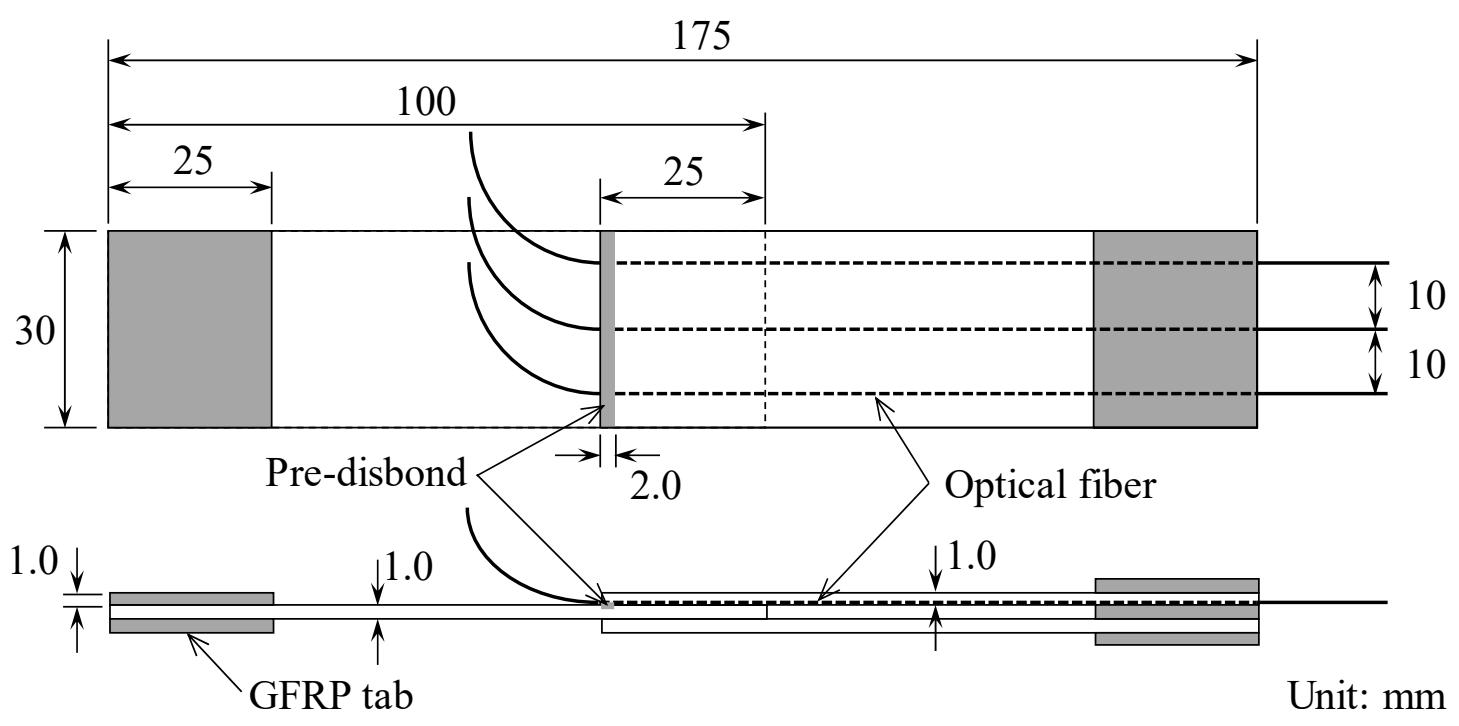

(b)

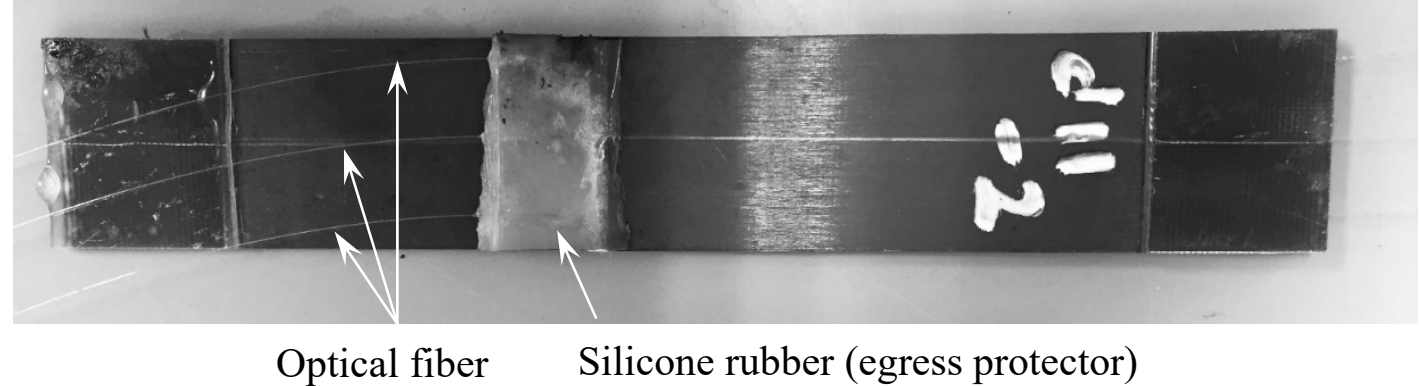

(c)

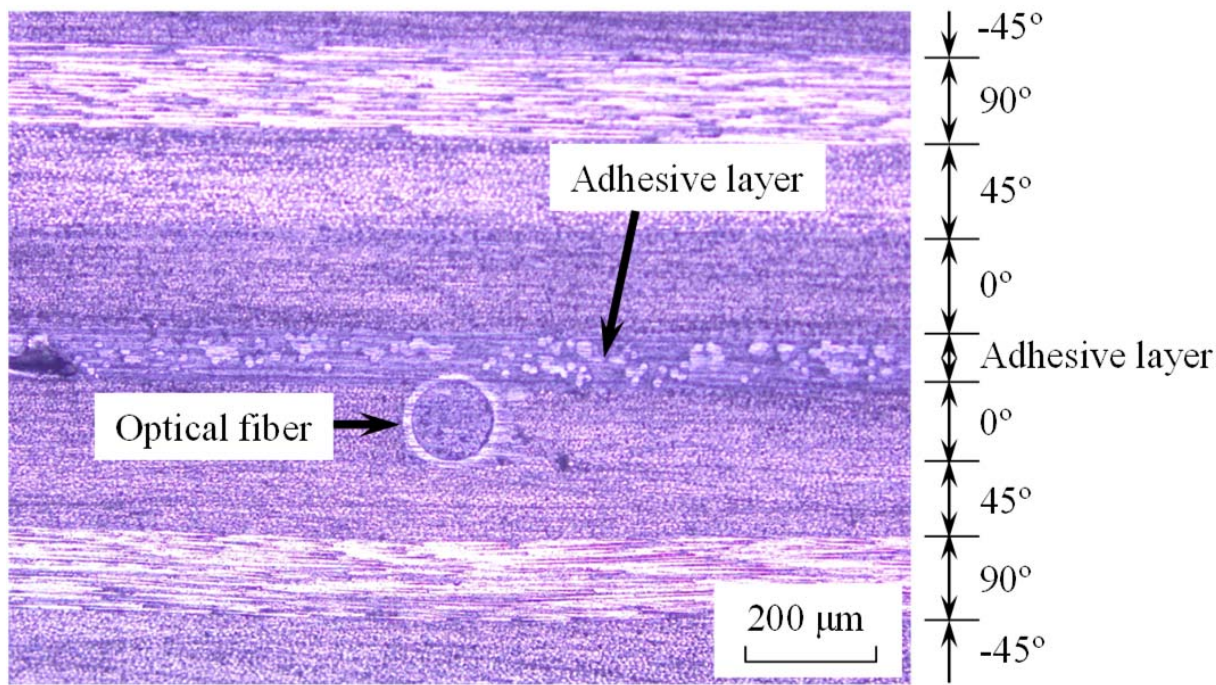

Figure 1 


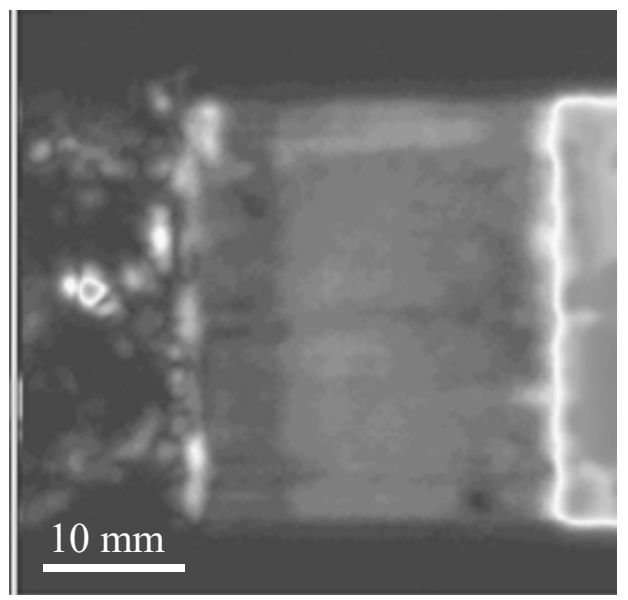

(a) $N=0$

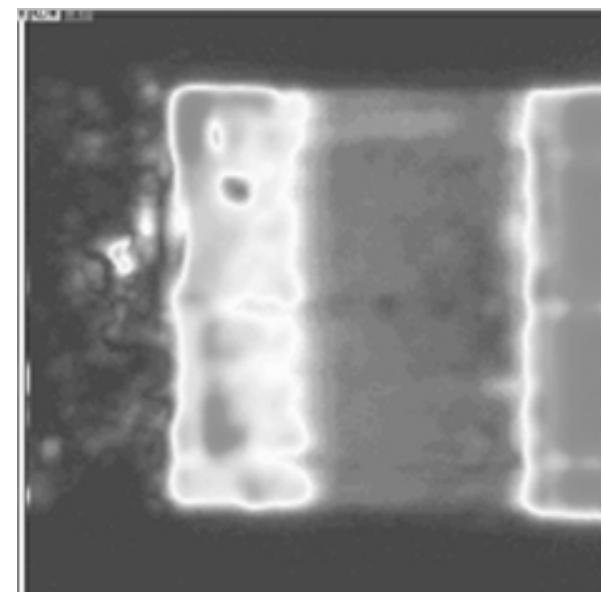

(c) $N=4000$

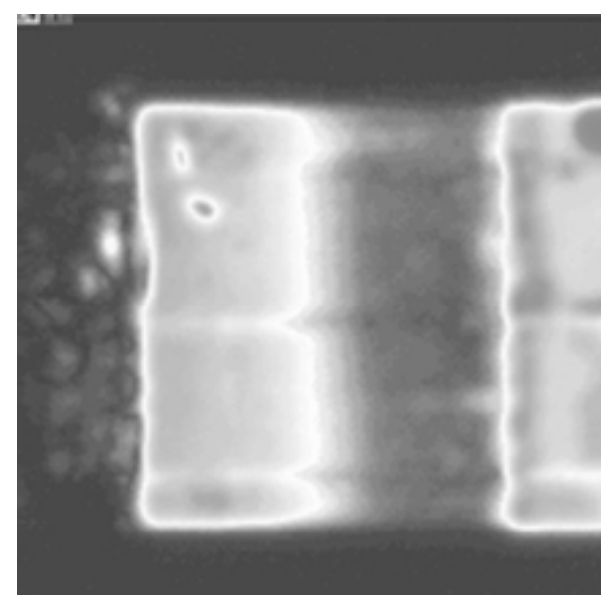

(e) $N=8000$

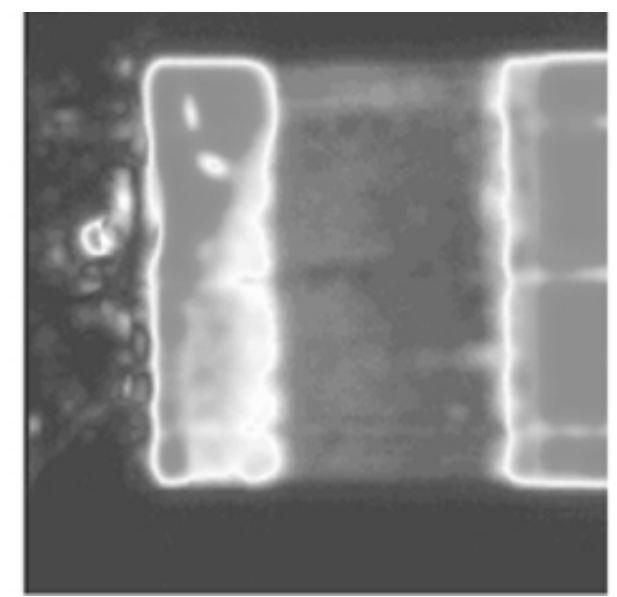

(b) $N=2000$

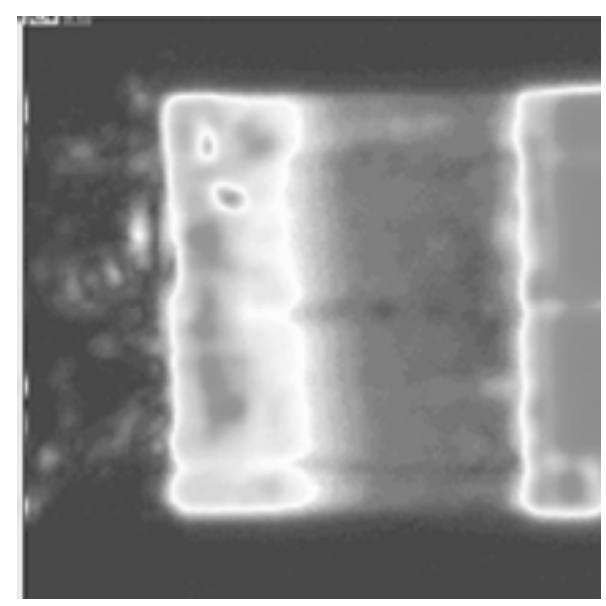

(d) $N=6000$

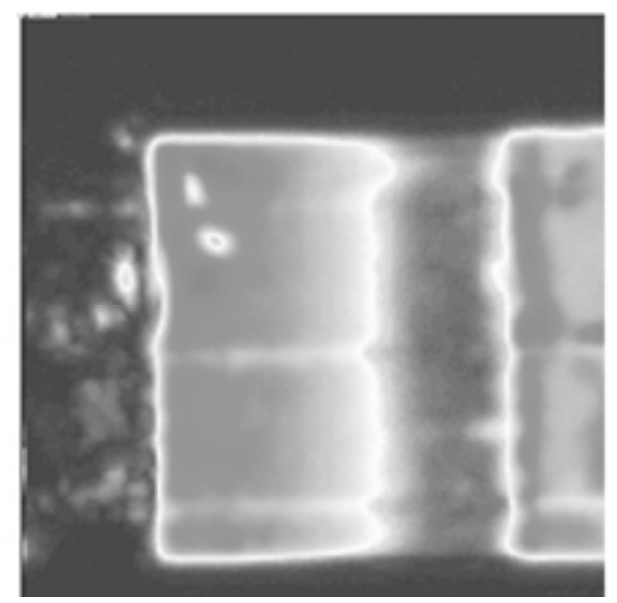

(f) $N=10000$

Figure 2 
(a) FBG \#1

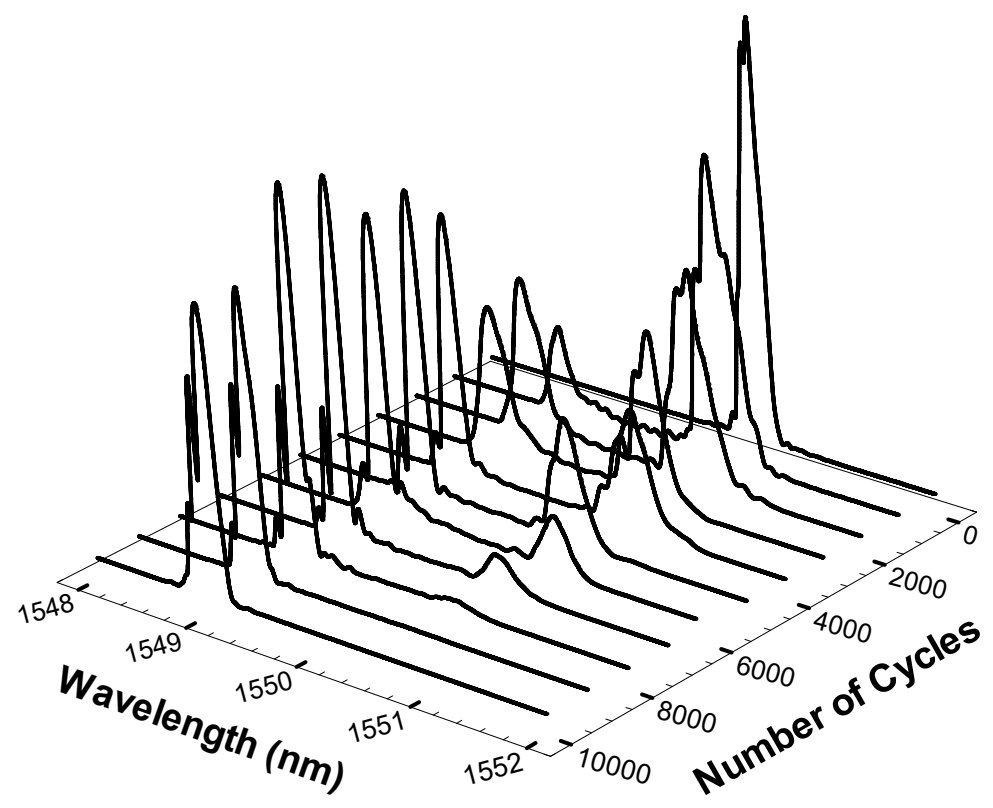

(b) FBG \#2

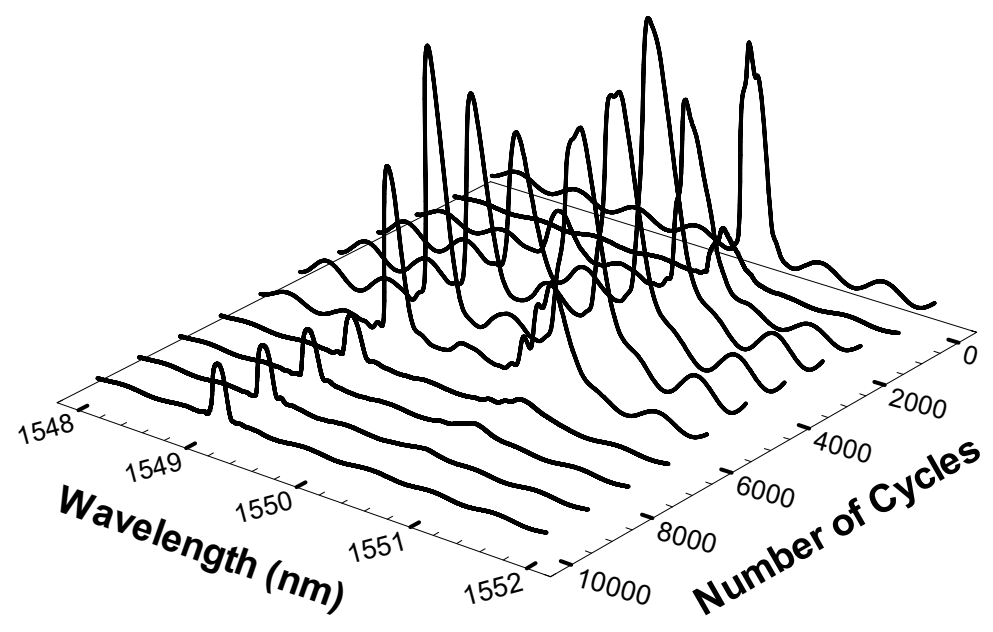

(c) FBG \#3

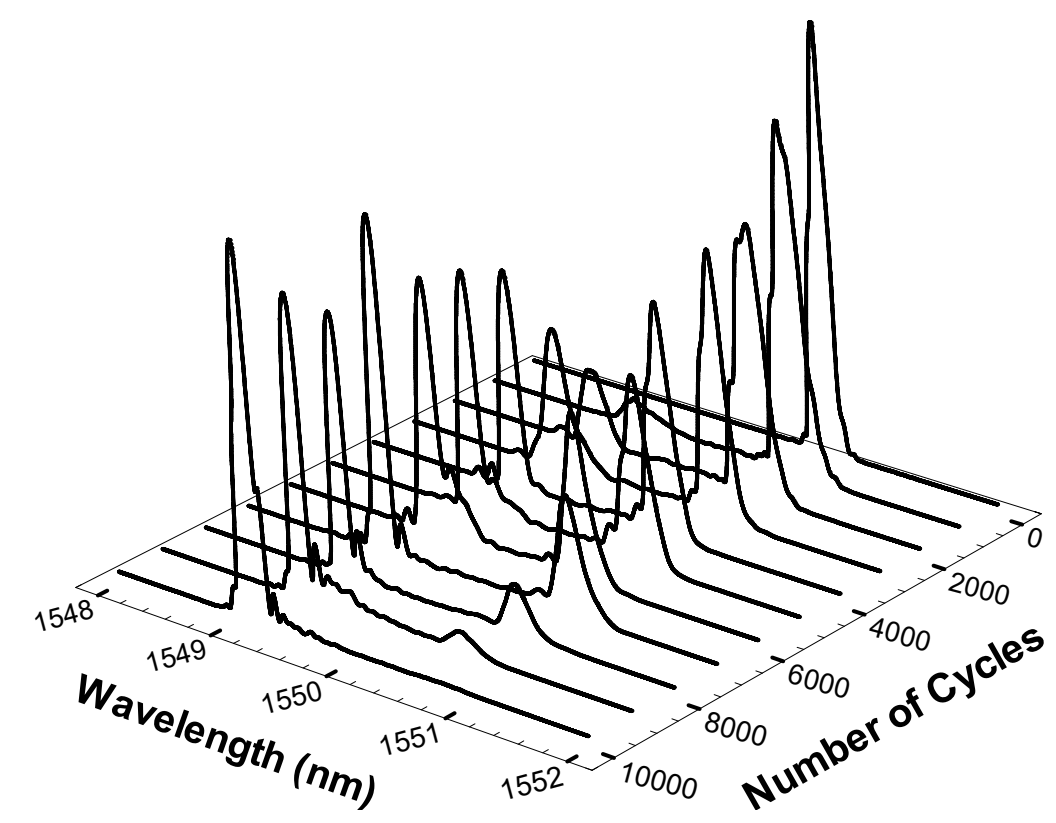

Figure 3 


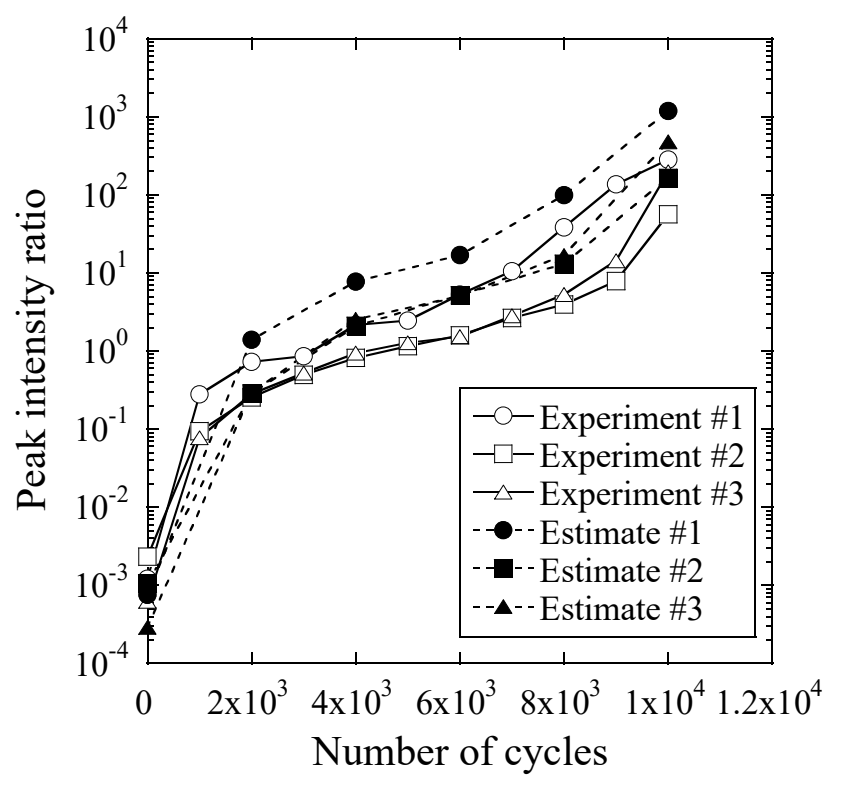

Figure 4 


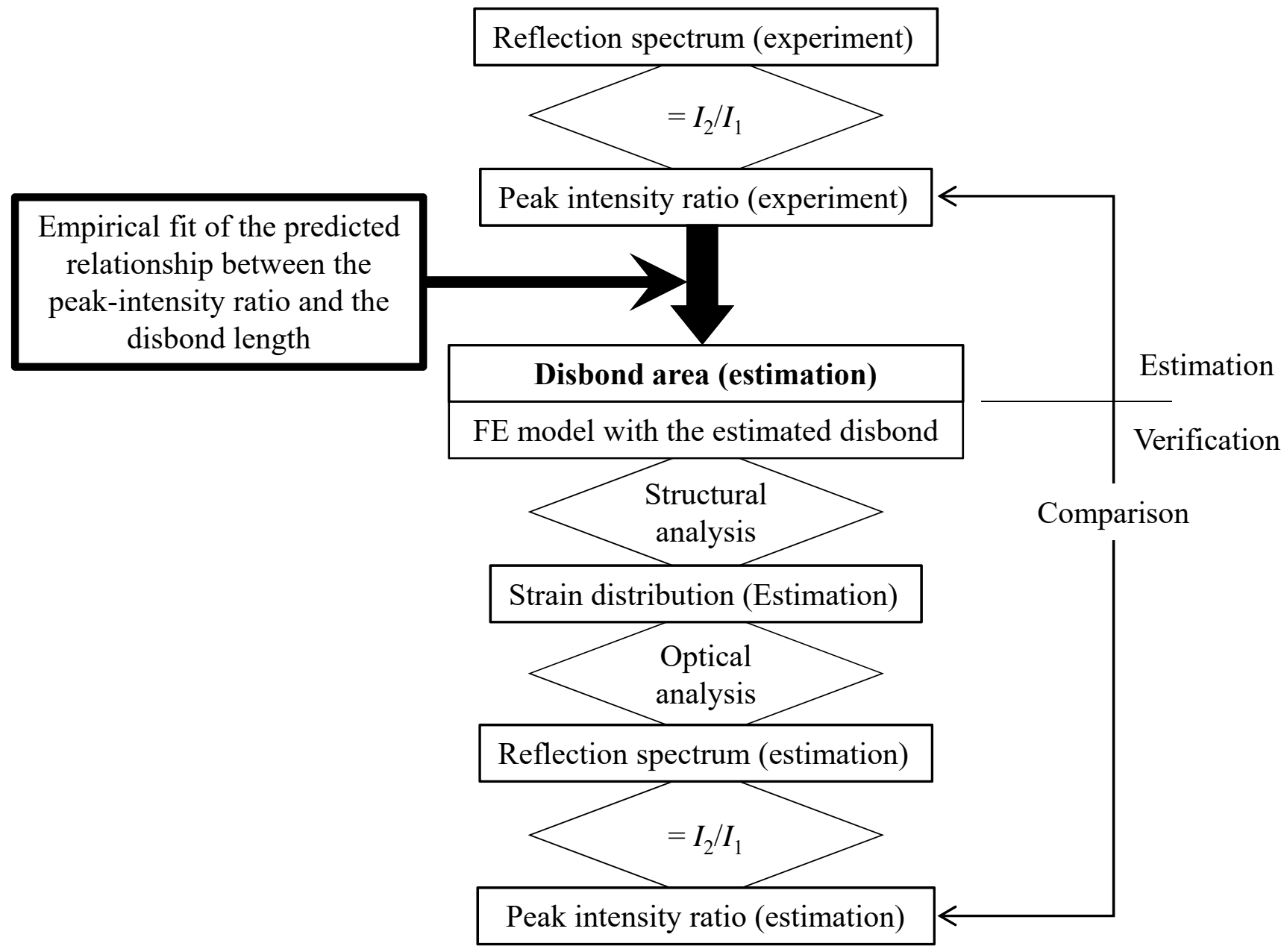




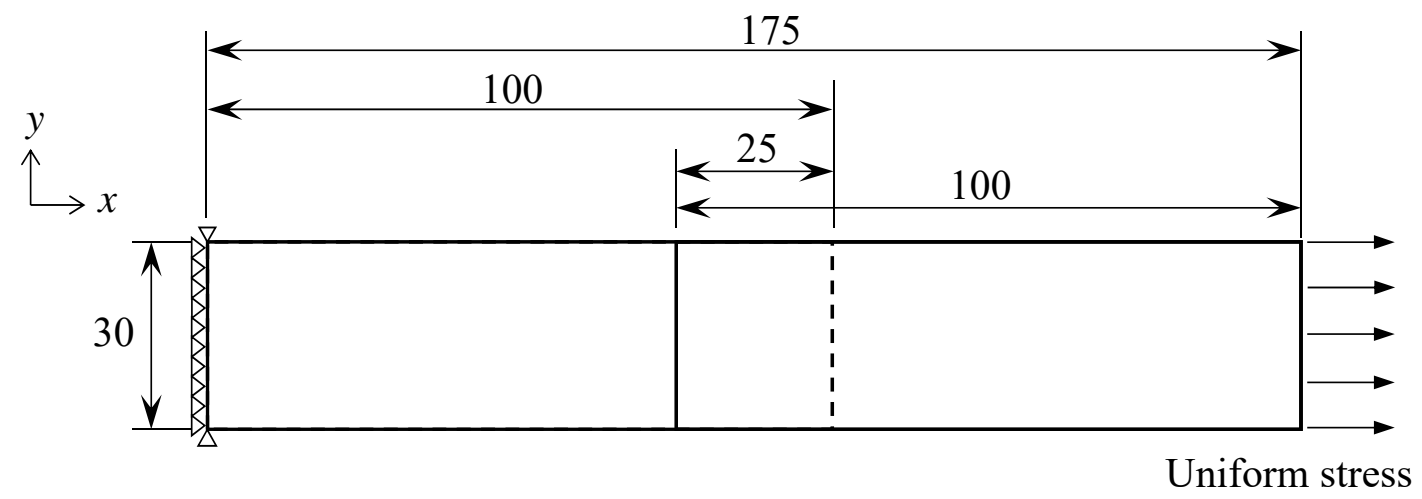

$\stackrel{Z}{Z} \underset{ }{\longrightarrow} X$

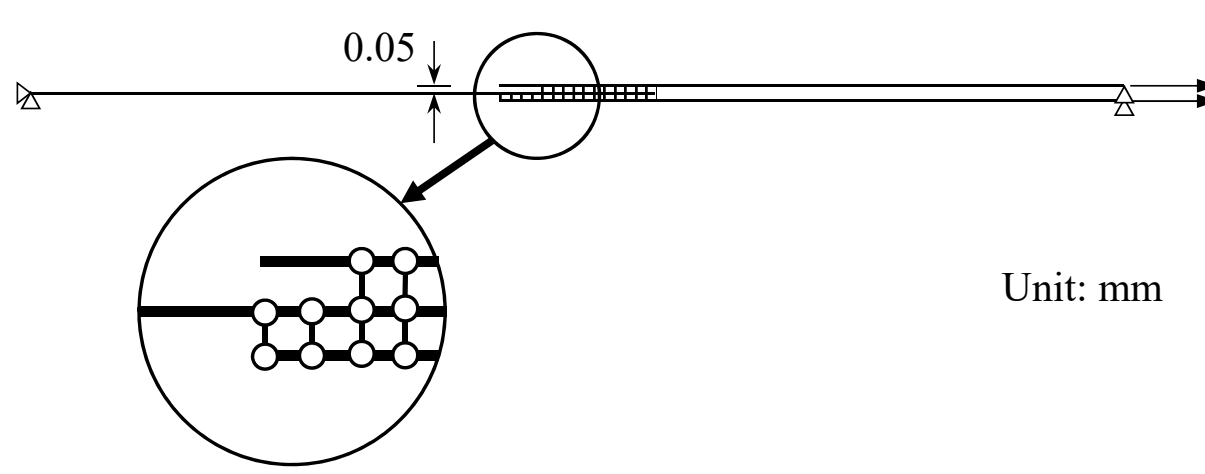

(a) Schematic

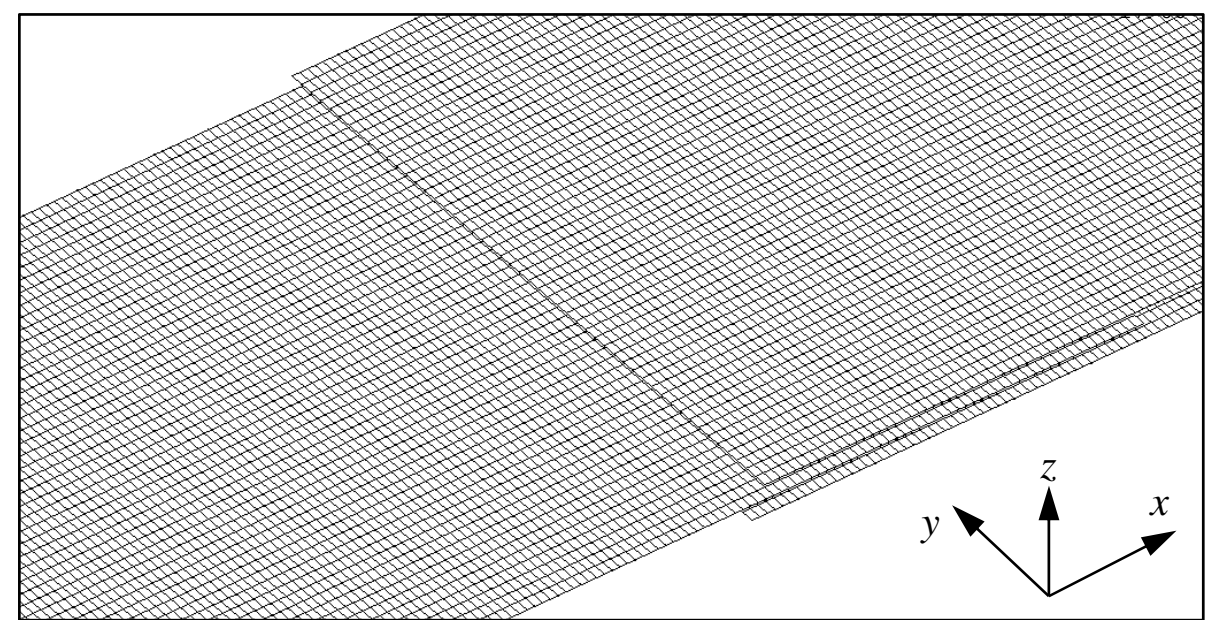

(b) Magnified view near the bonded section 


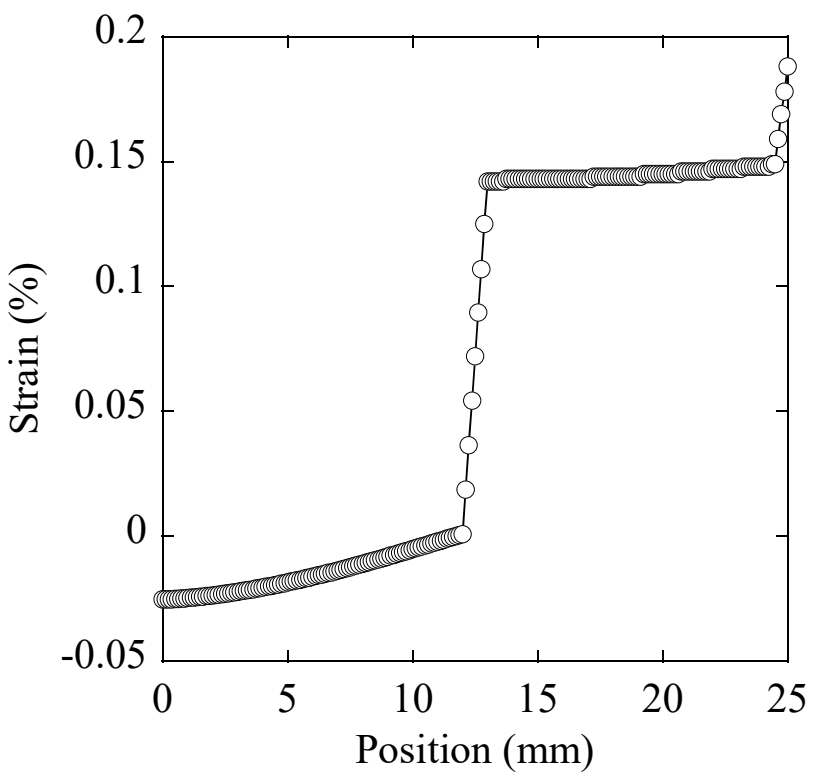

(a)

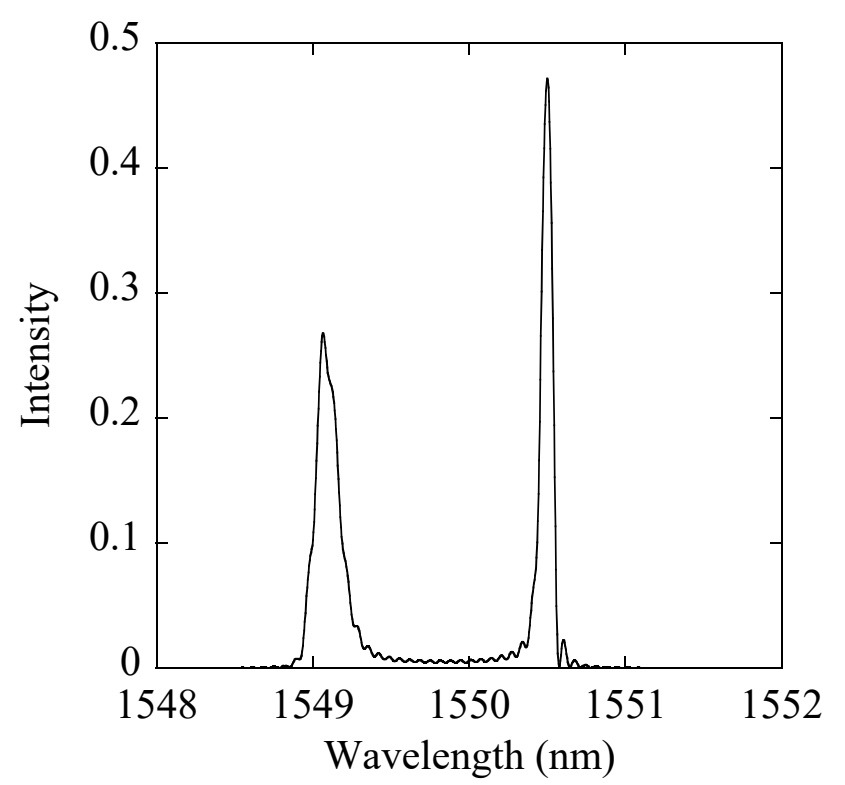

(b)

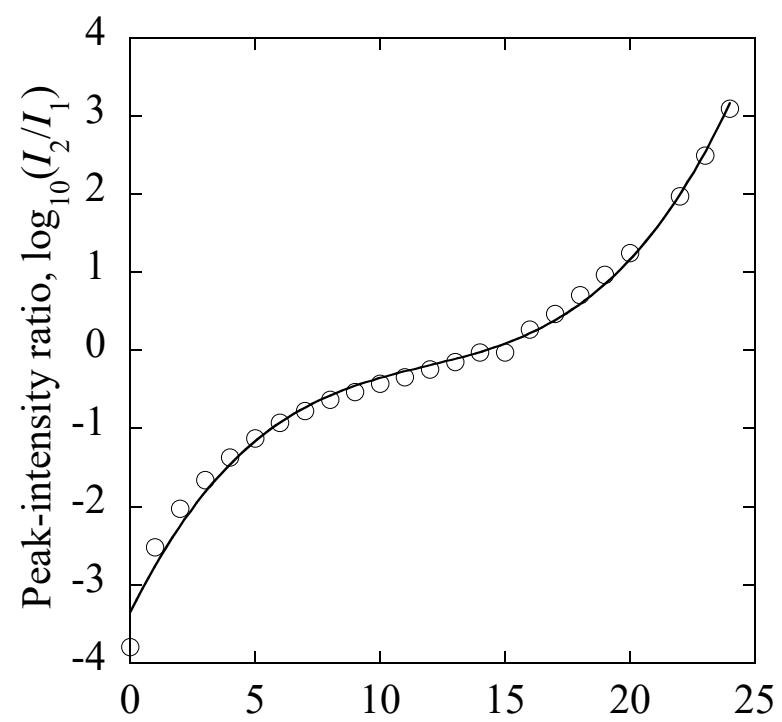

(c)

Disbond length, mm

Figure 7 


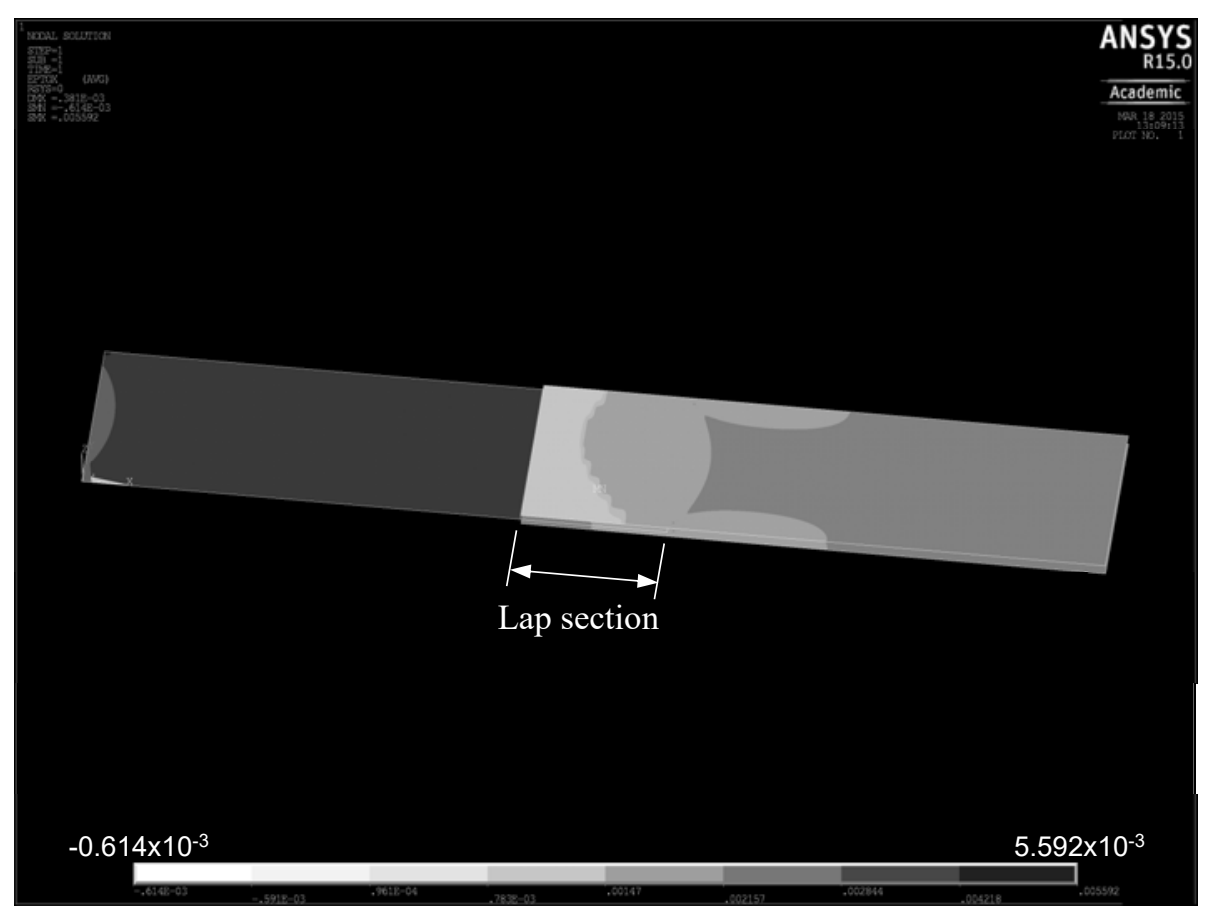

(a) $N=2000$

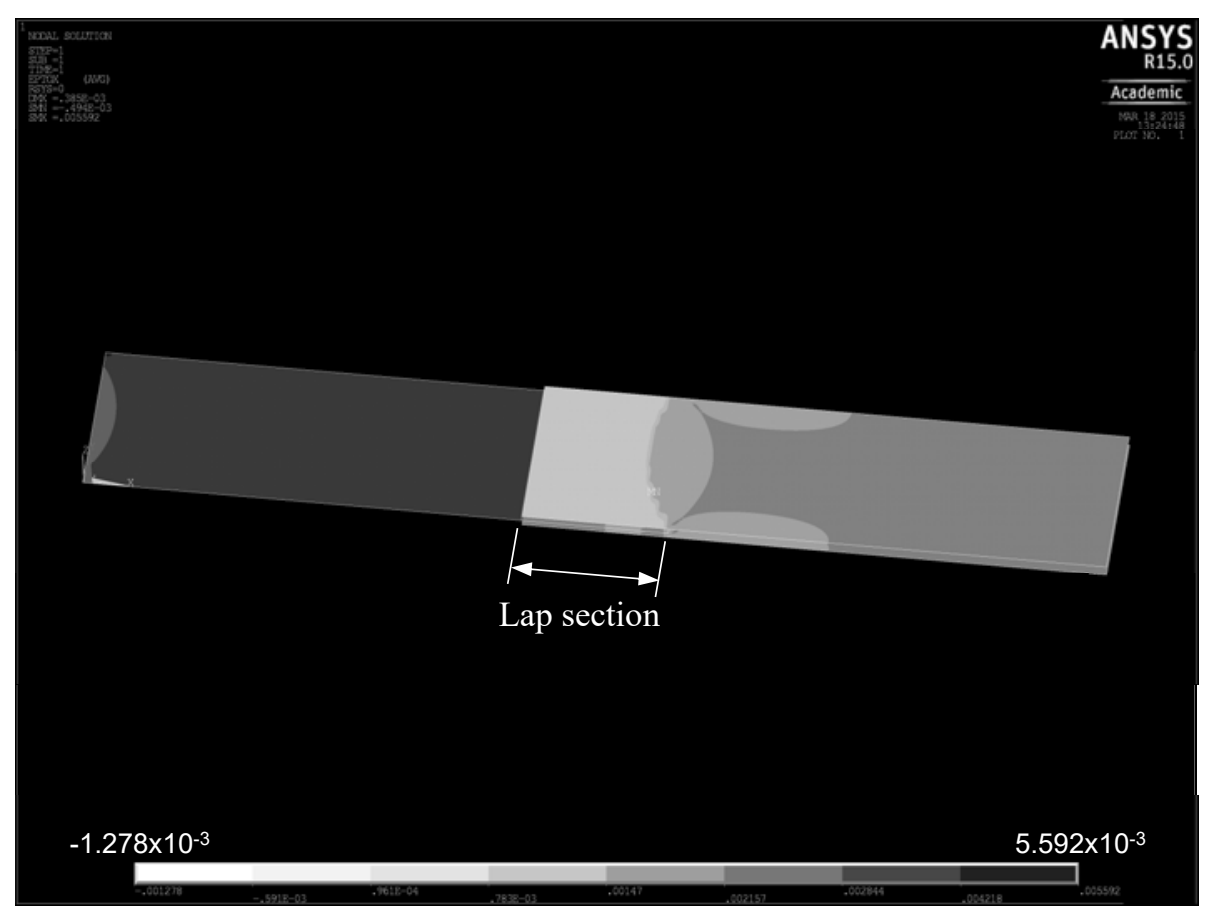

(b) $N=8000$

Figure 8 
(a) FBG \#1

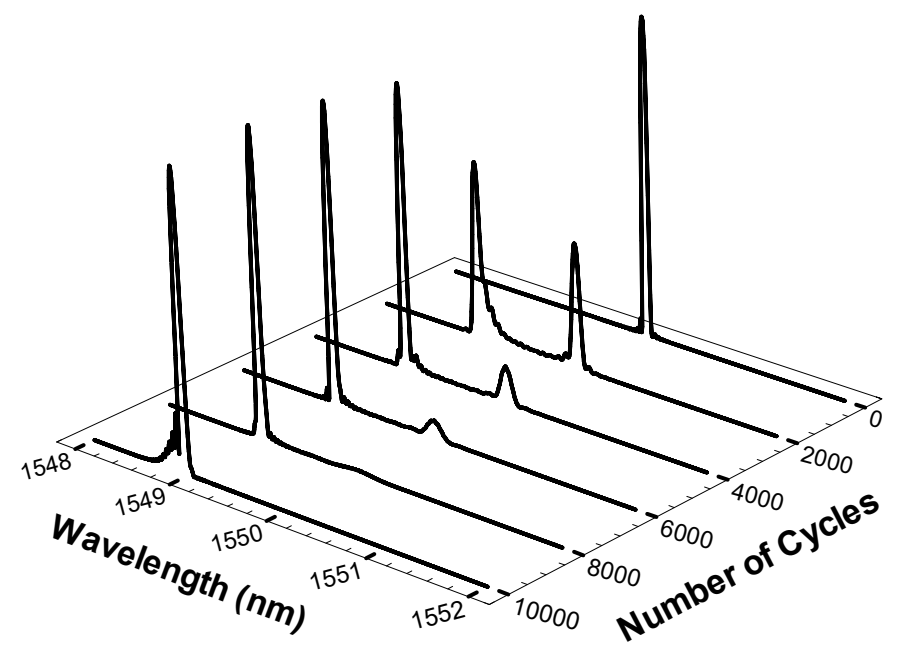

(b) FBG \#2

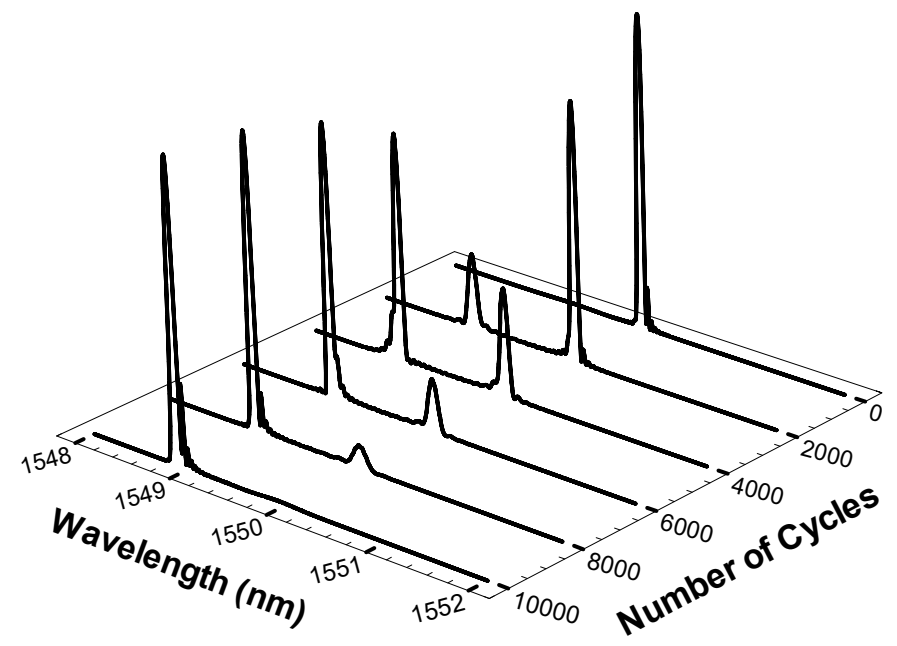

(c) FBG \#3

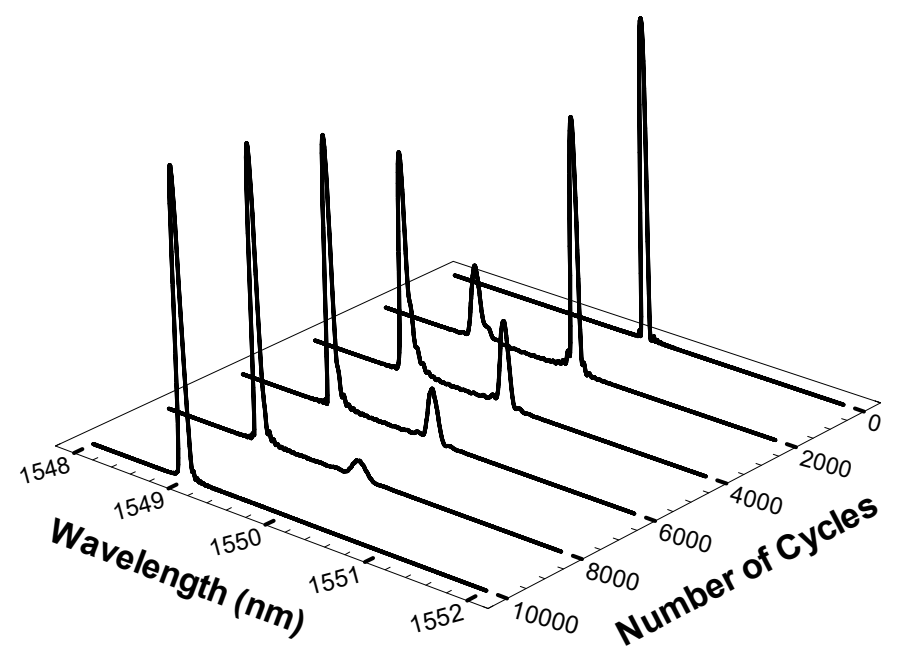

Figure 9 


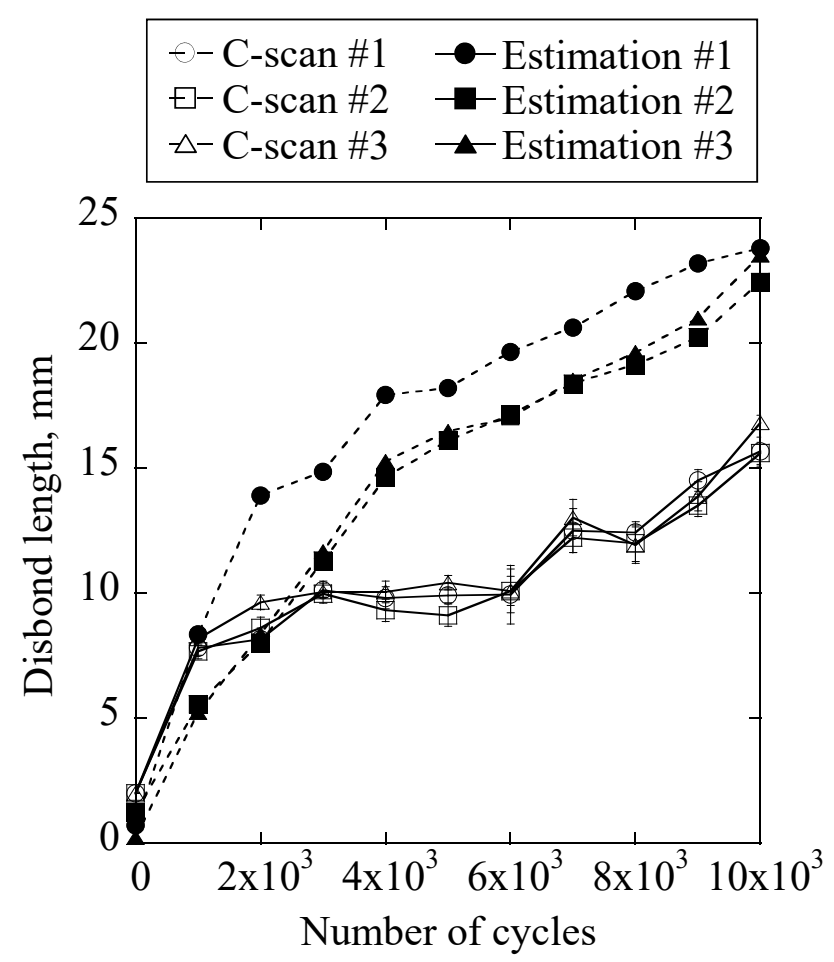

Figure 10 


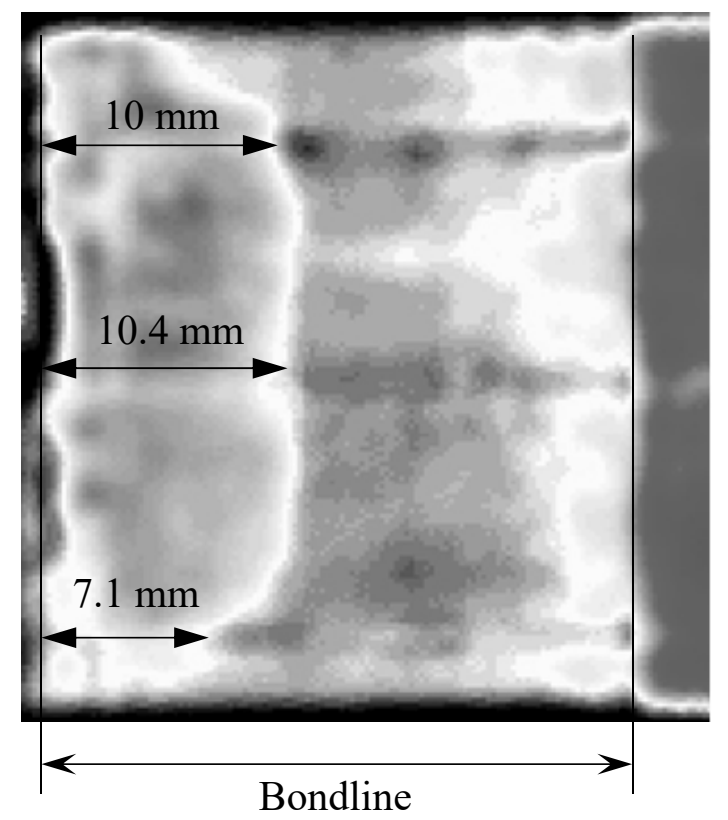

(a) Ultrasonic C-scan image

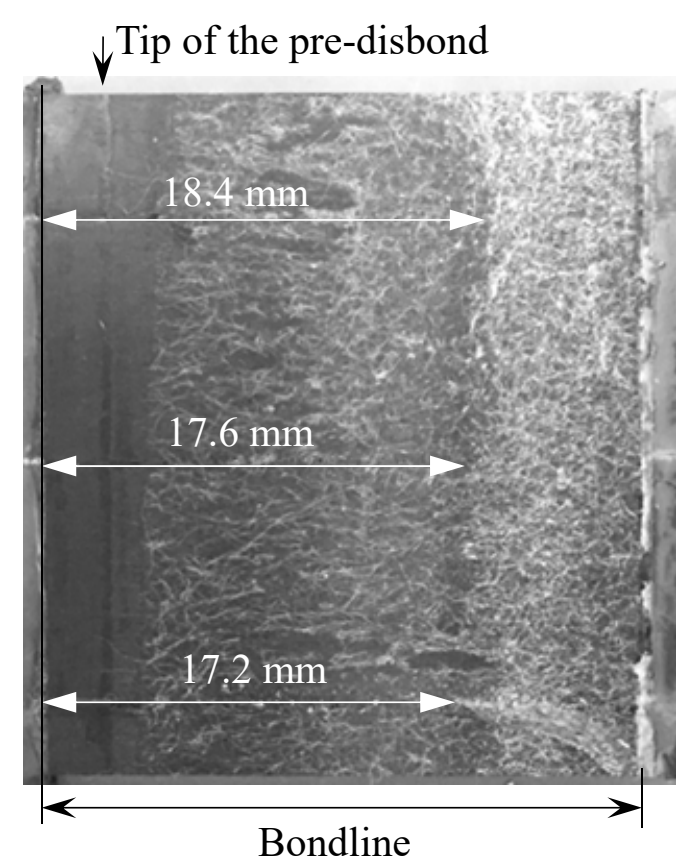

(c) Microphotograph

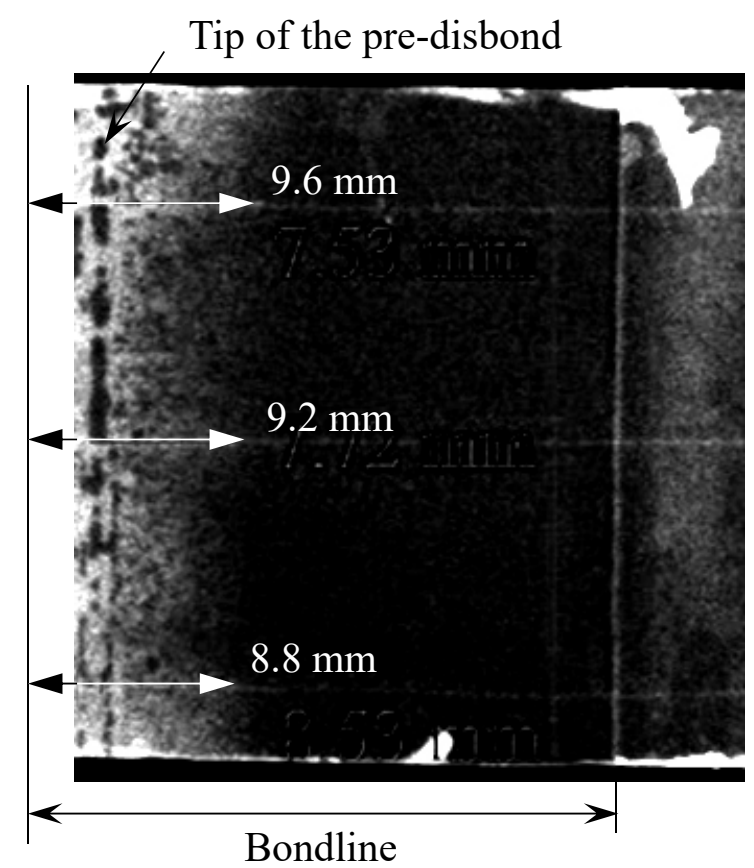

(b) Soft X-ray photograph 


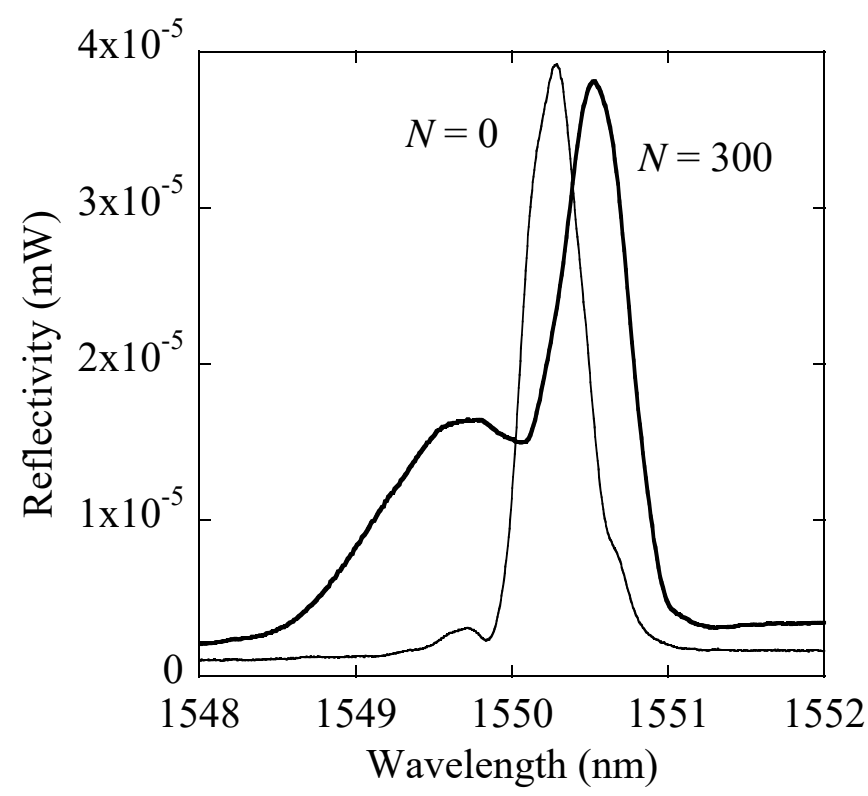

(a) Reflection spectrum

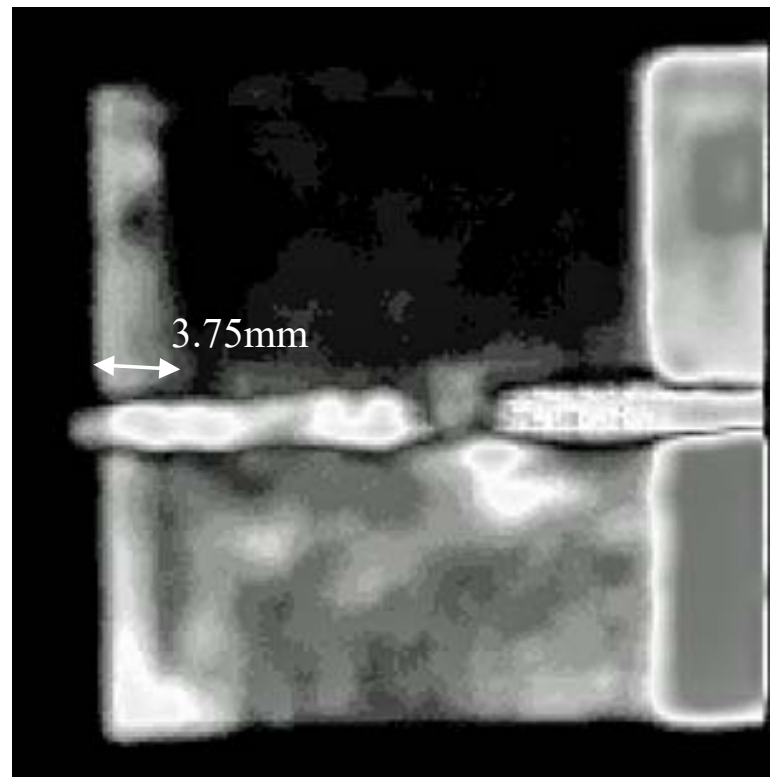

(b) Ultrasonic C-scan image

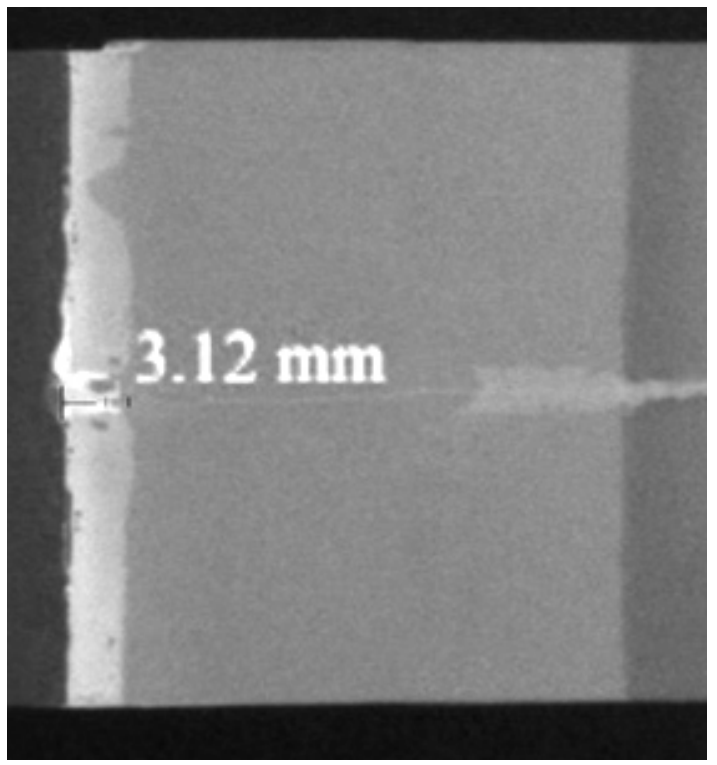

Figure 12

(c) Soft X-ray photograph 
(a)

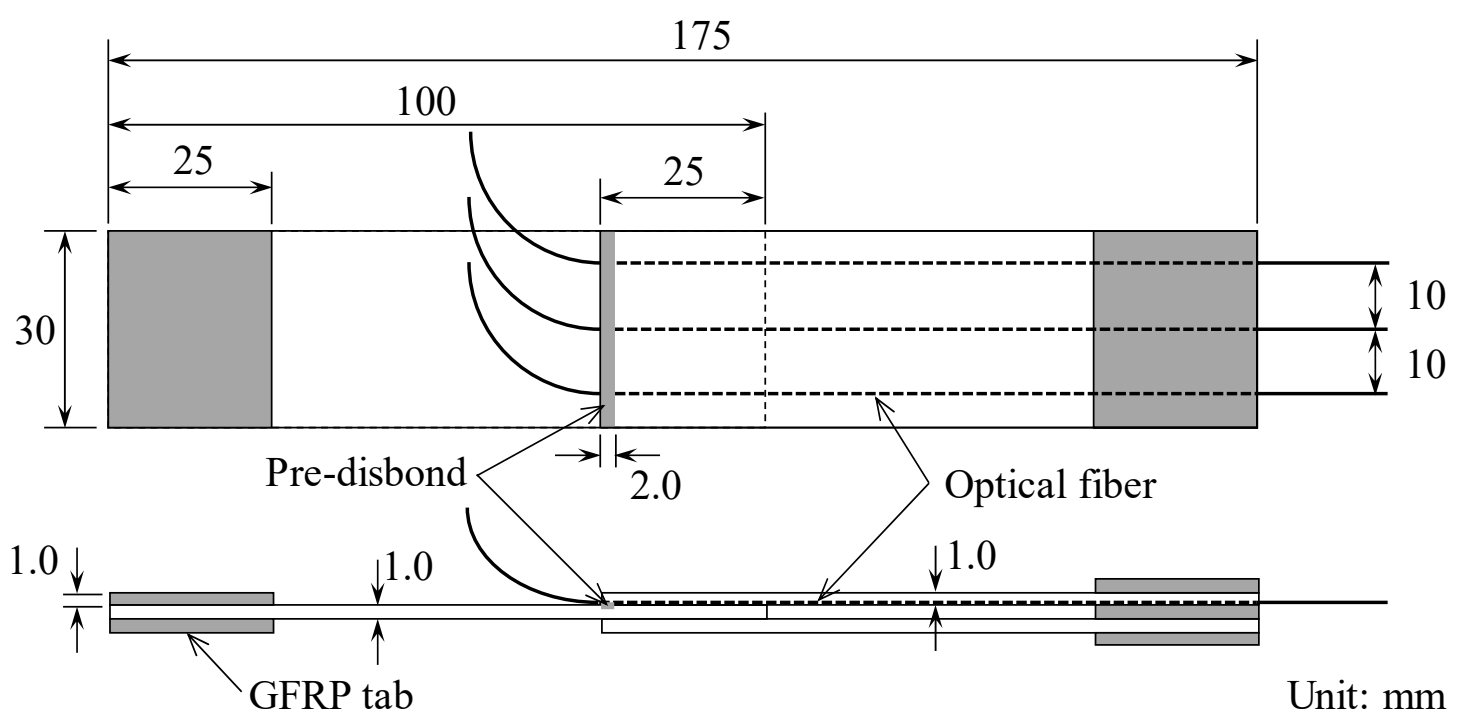

(b)

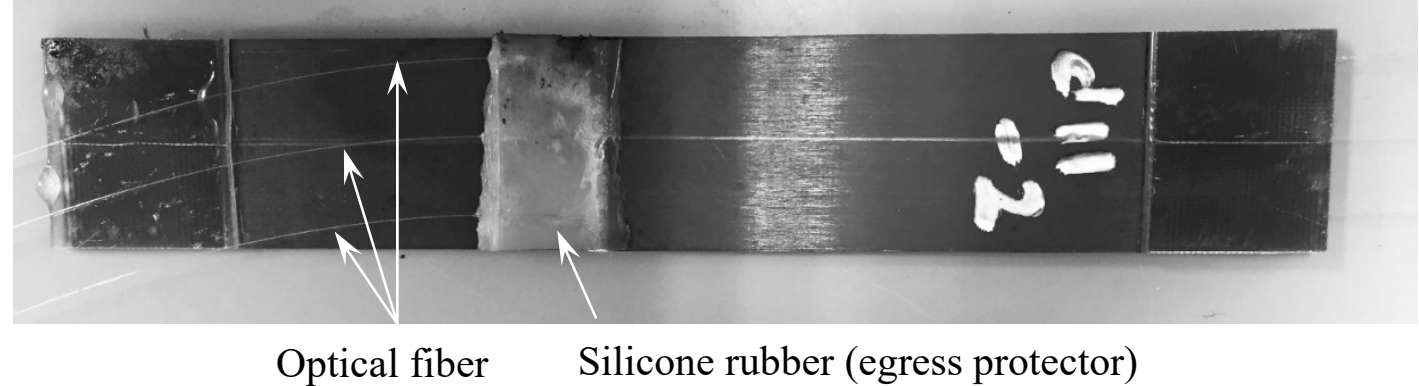

(c)

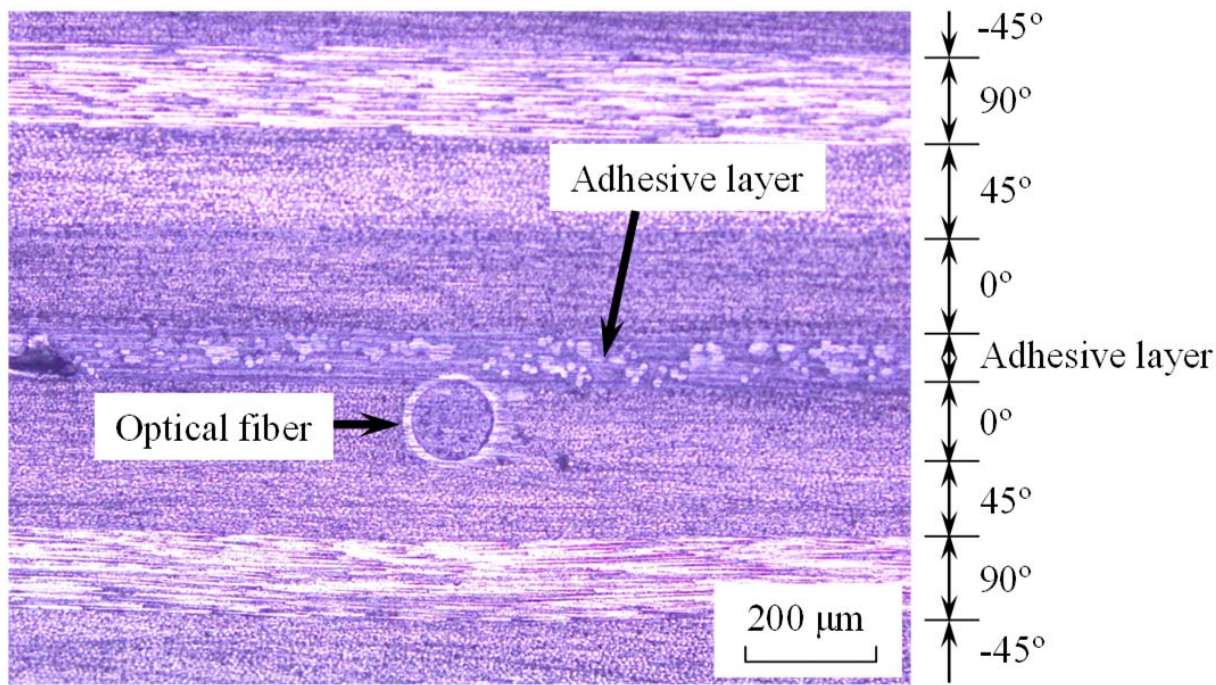

Figure 1 


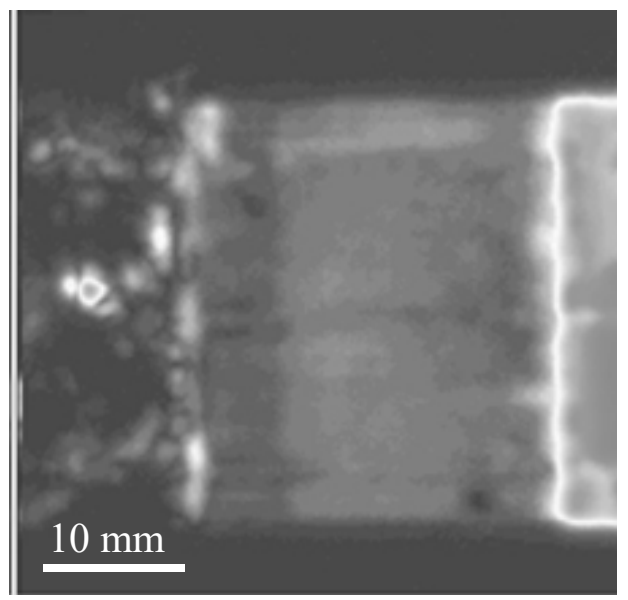

(a) $N=0$

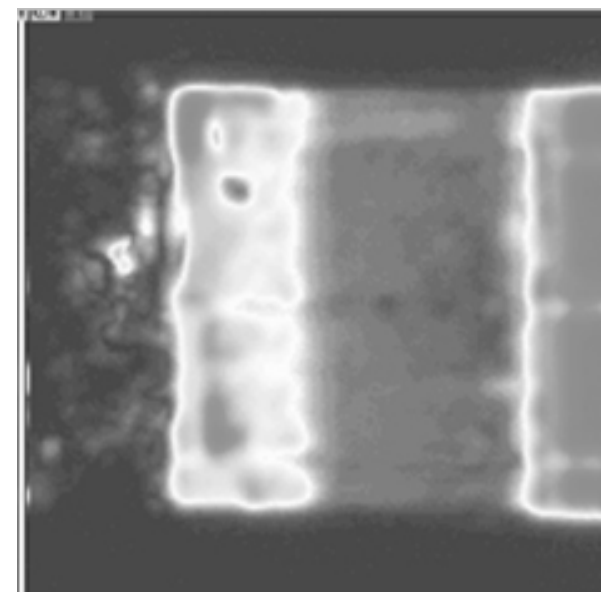

(c) $N=4000$

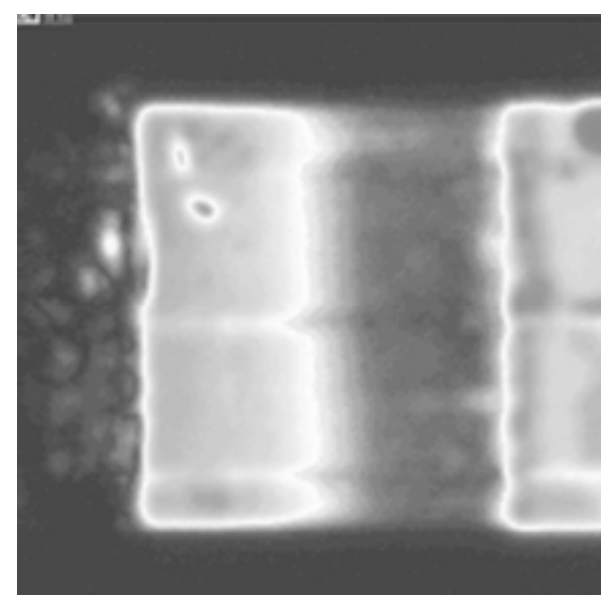

(e) $N=8000$

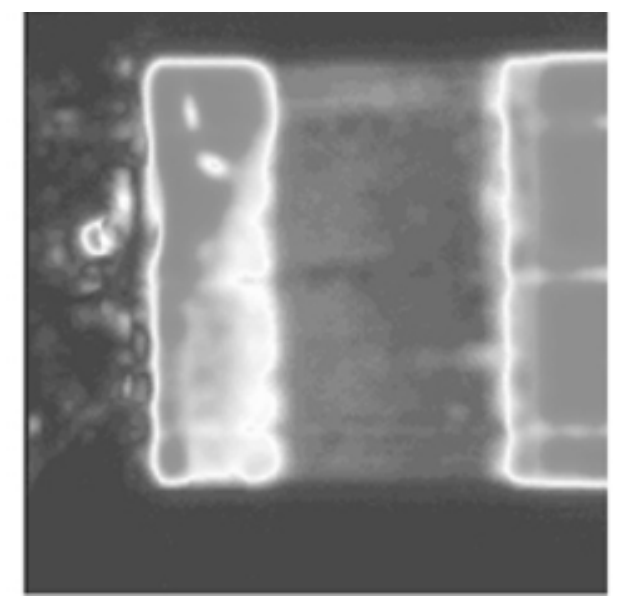

(b) $N=2000$

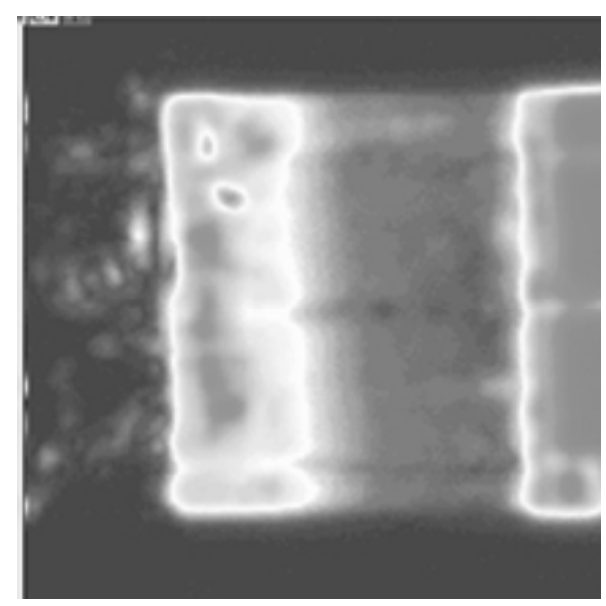

(d) $N=6000$

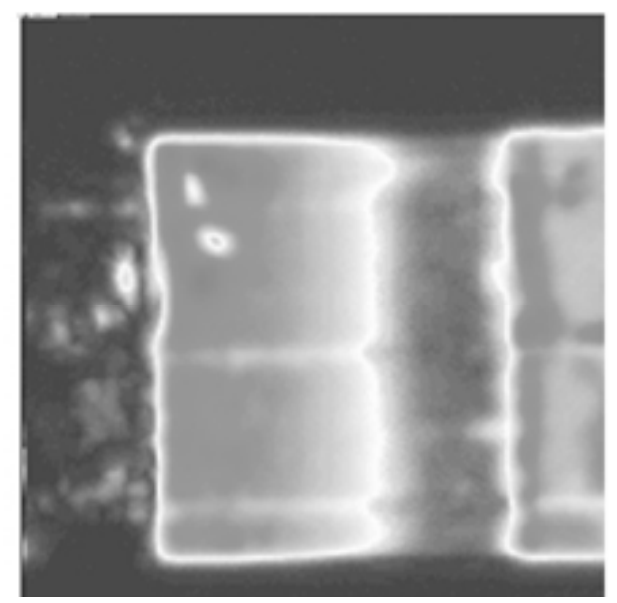

(f) $N=10000$

Figure 2 
(a) FBG \#1

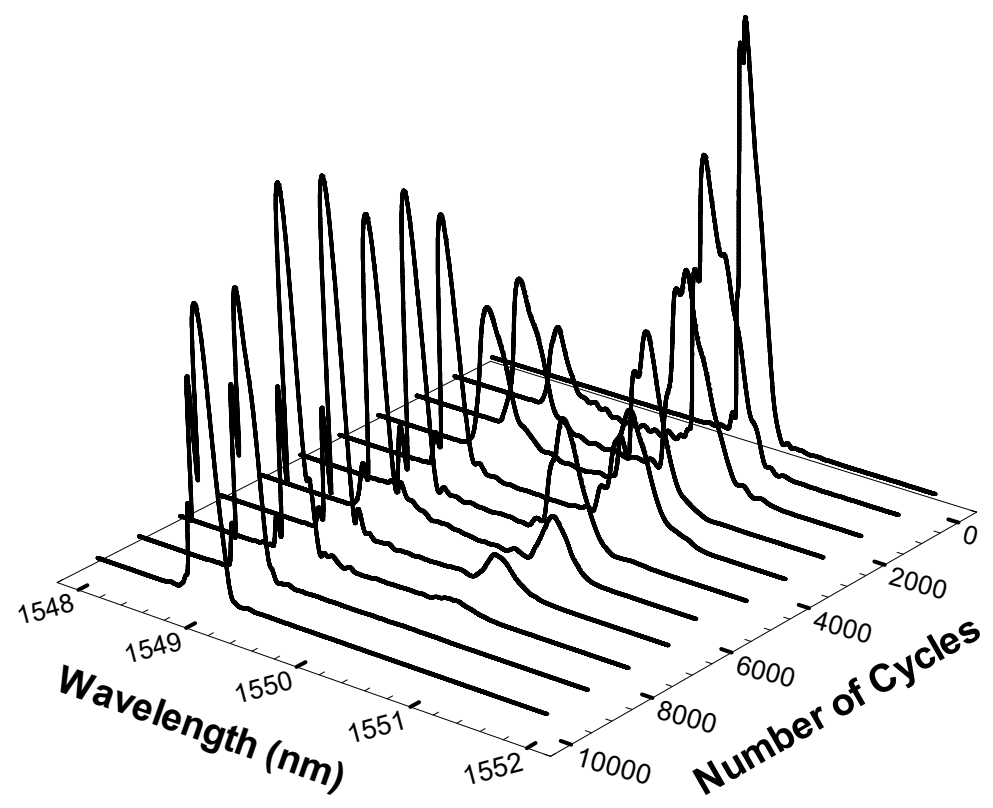

(b) FBG \#2

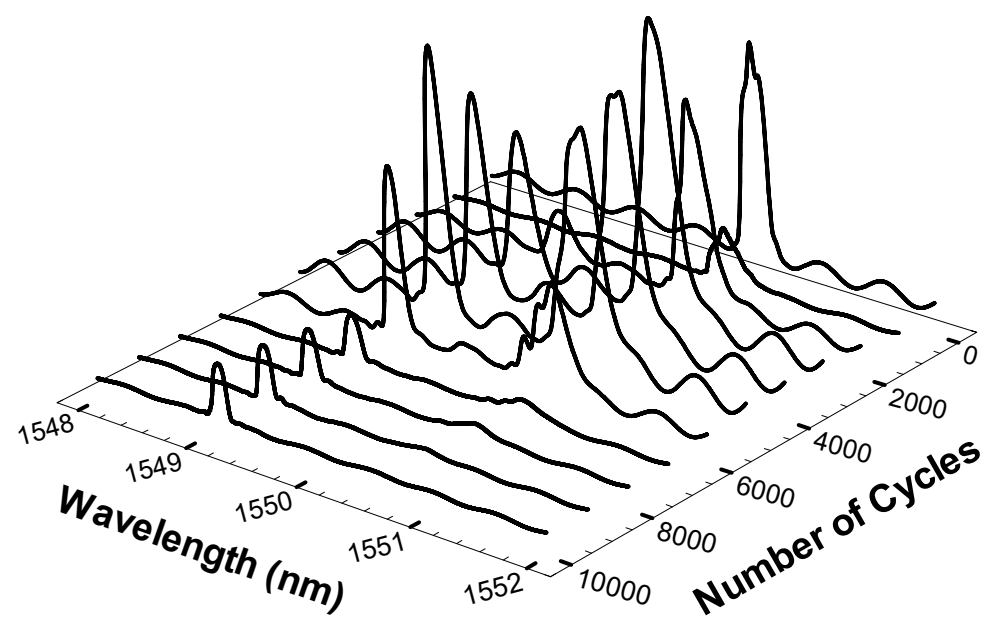

(c) FBG \#3

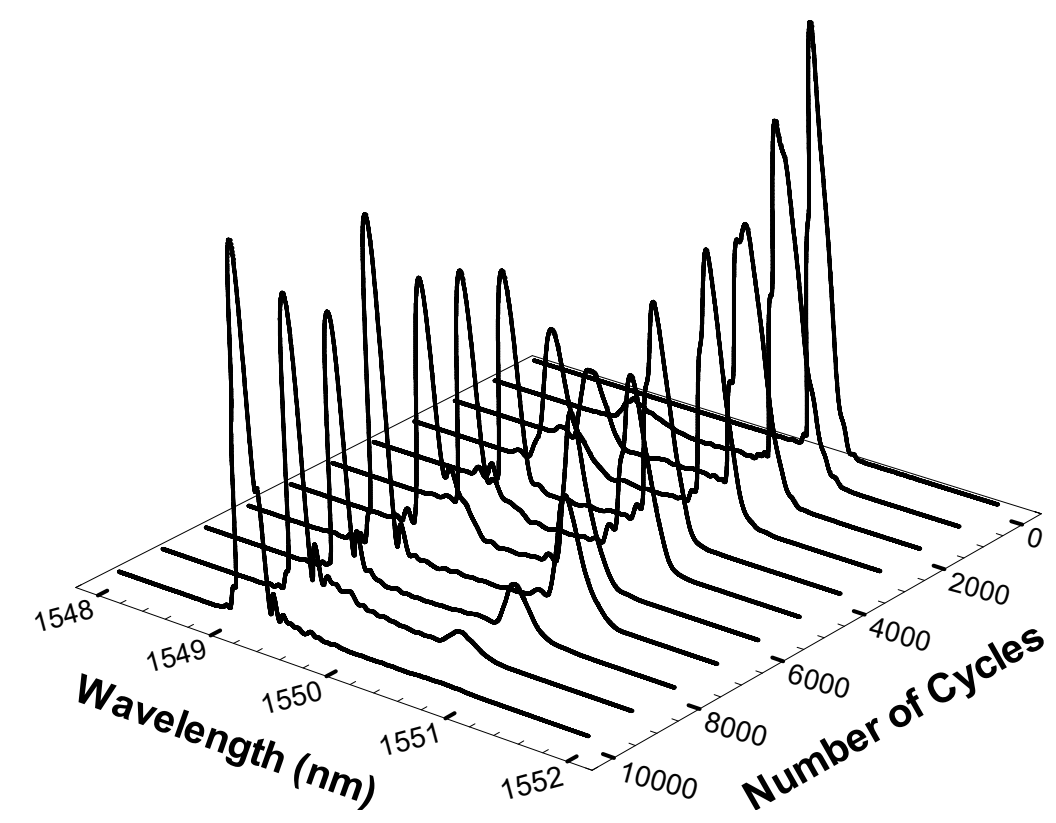

Figure 3 


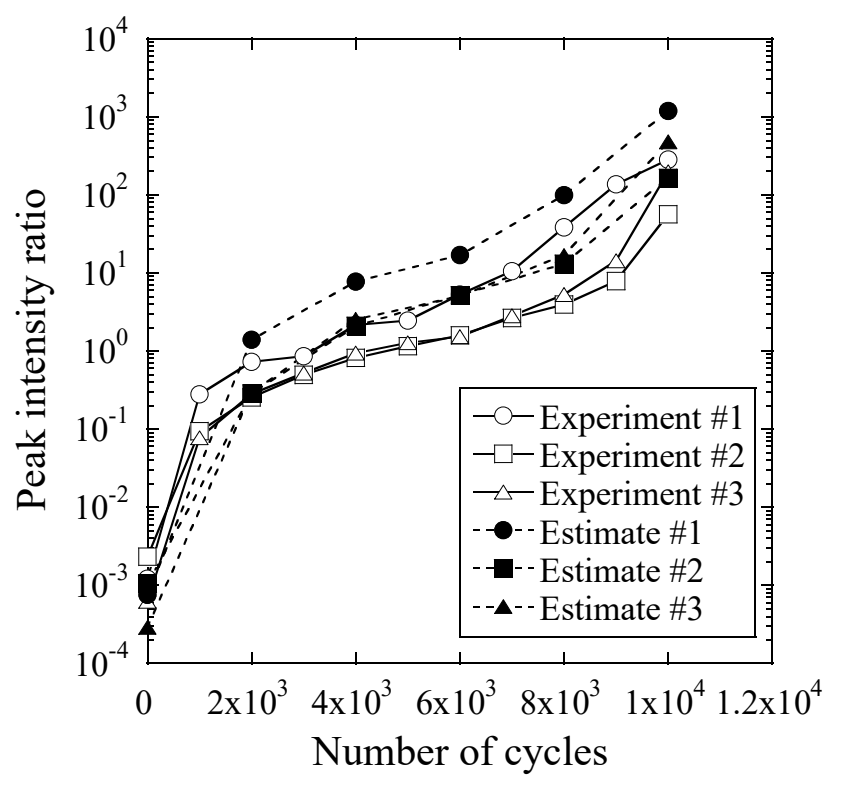

Figure 4 


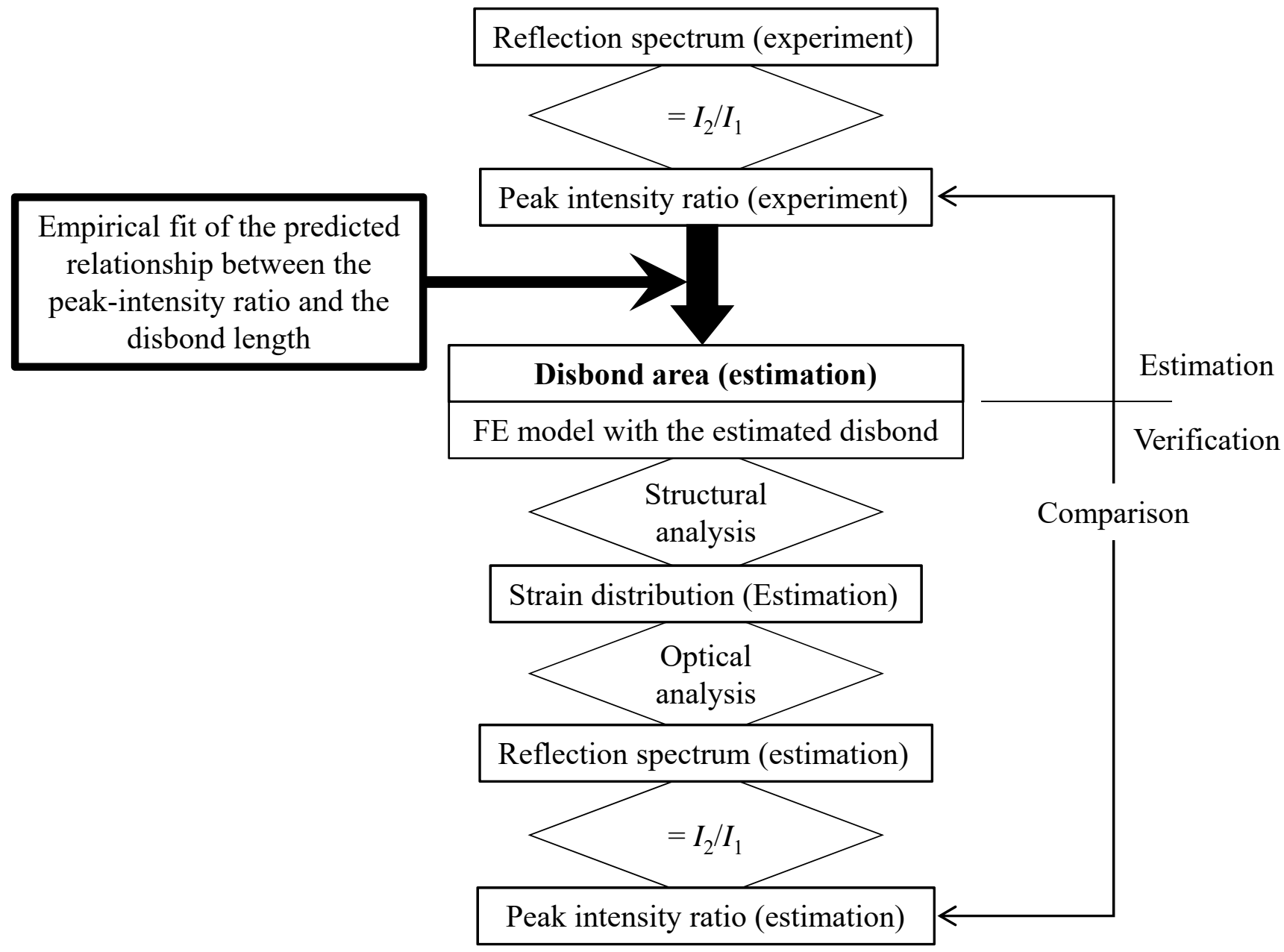




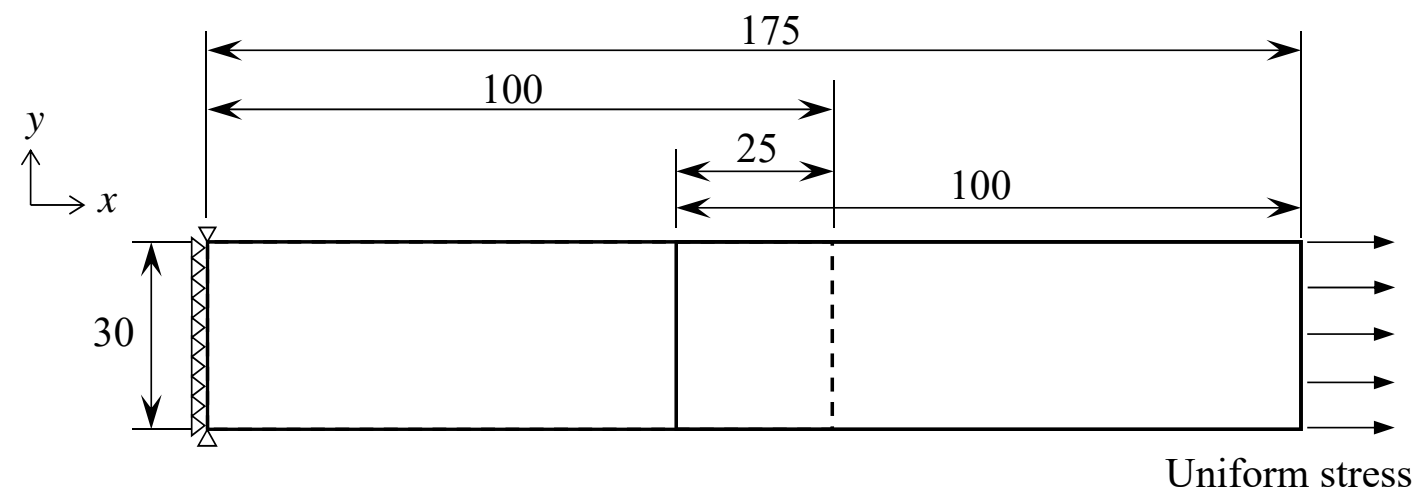

$\stackrel{Z}{Z} \underset{ }{\longrightarrow} X$

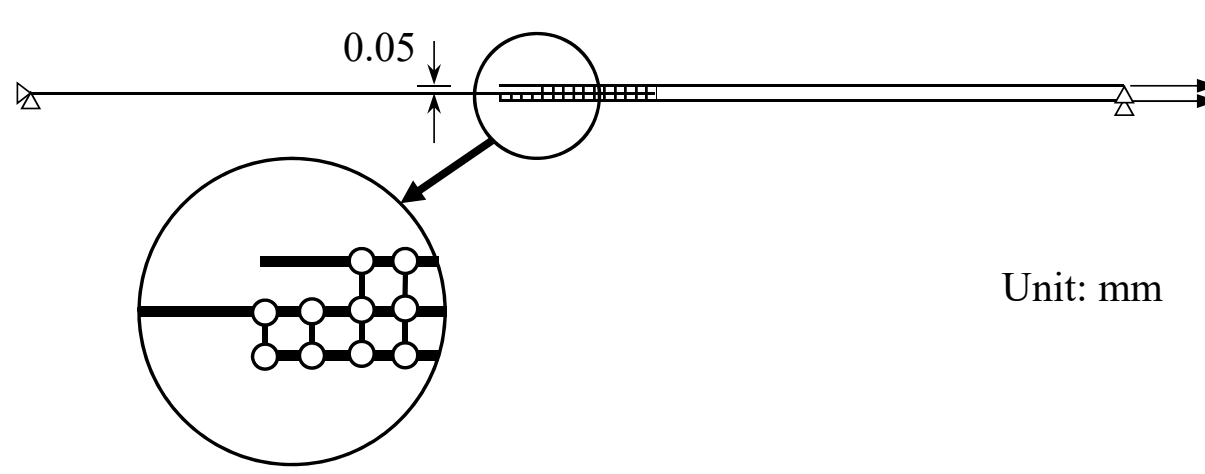

(a) Schematic

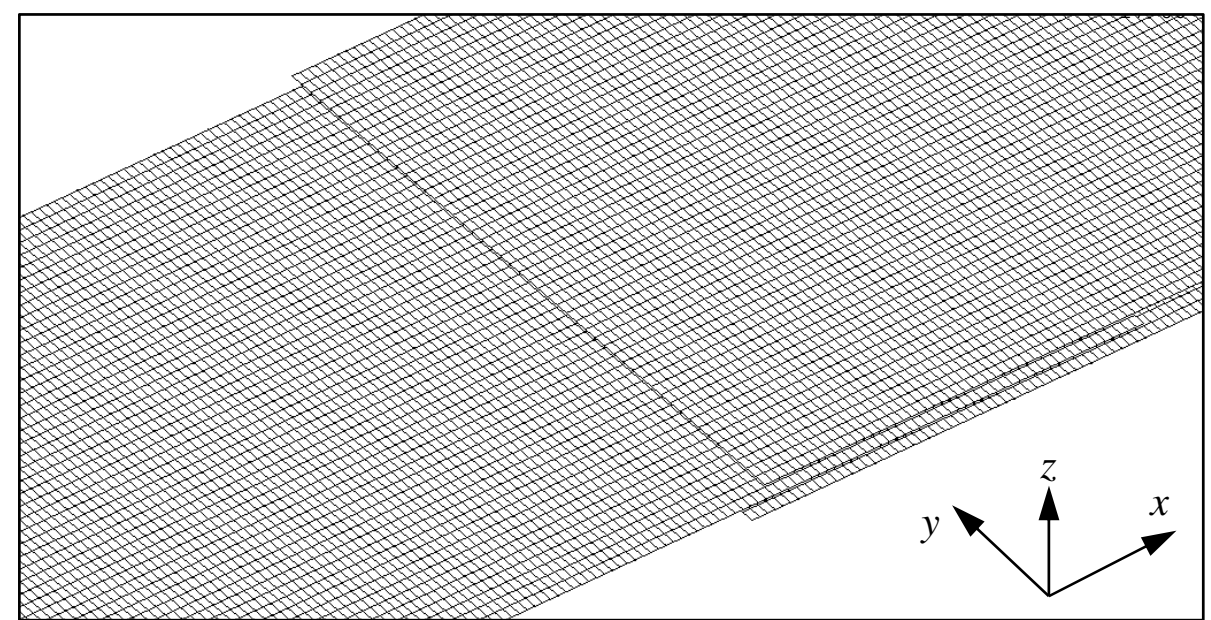

(b) Magnified view near the bonded section 


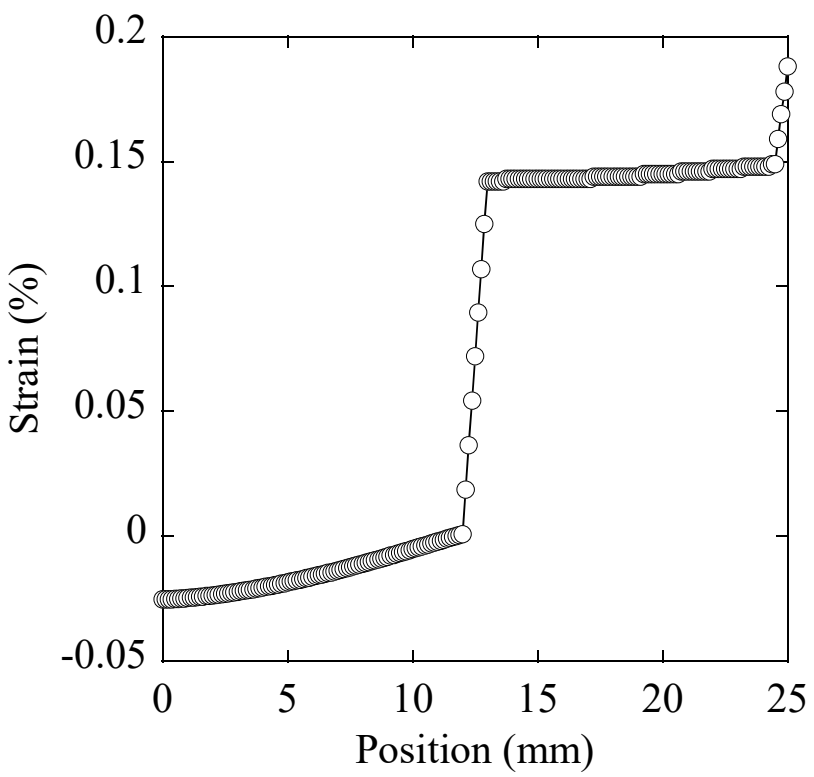

(a)

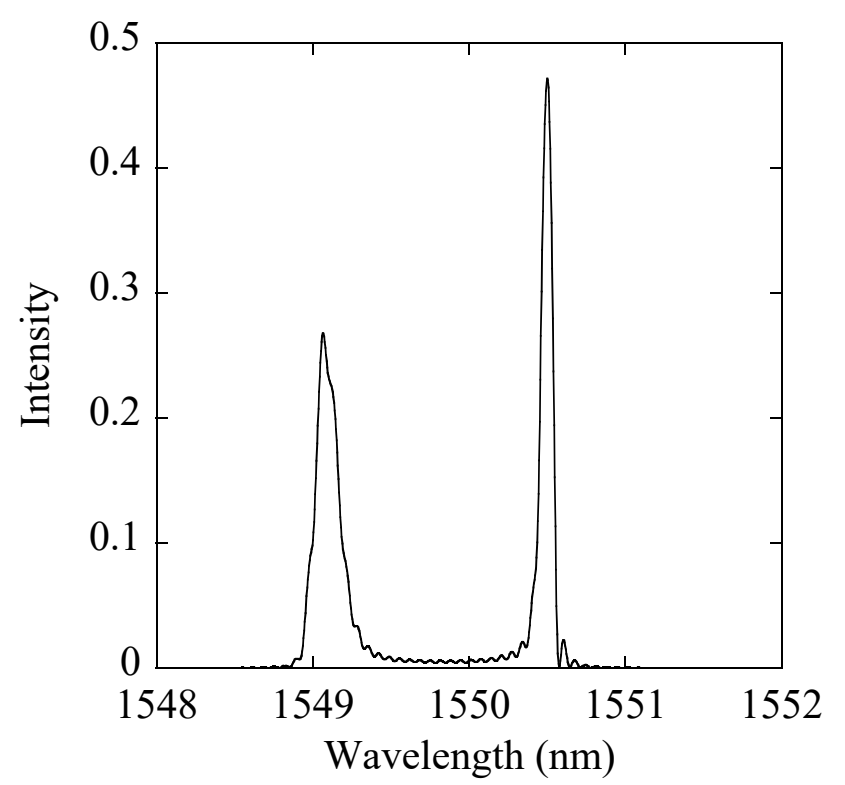

(b)

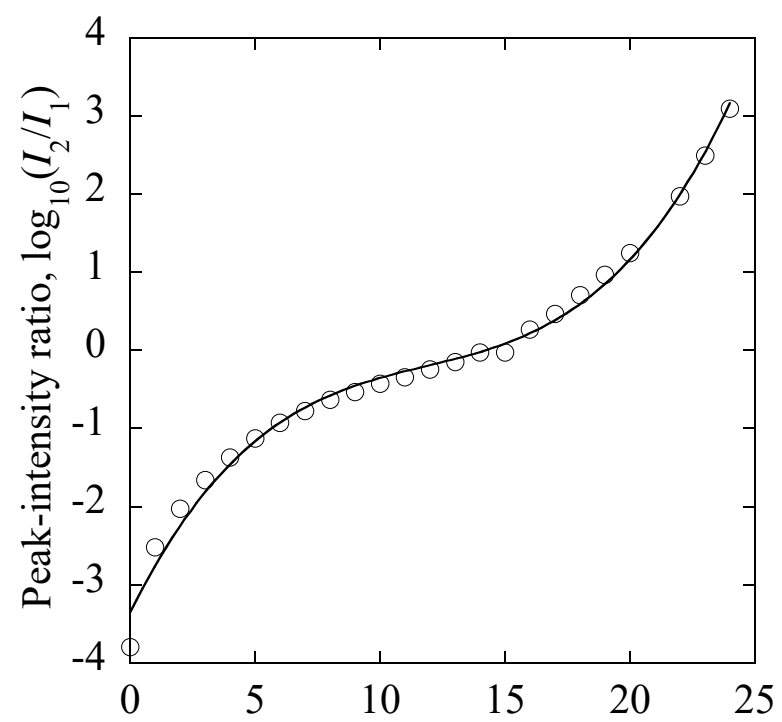

(c)

Disbond length, mm

Figure 7 


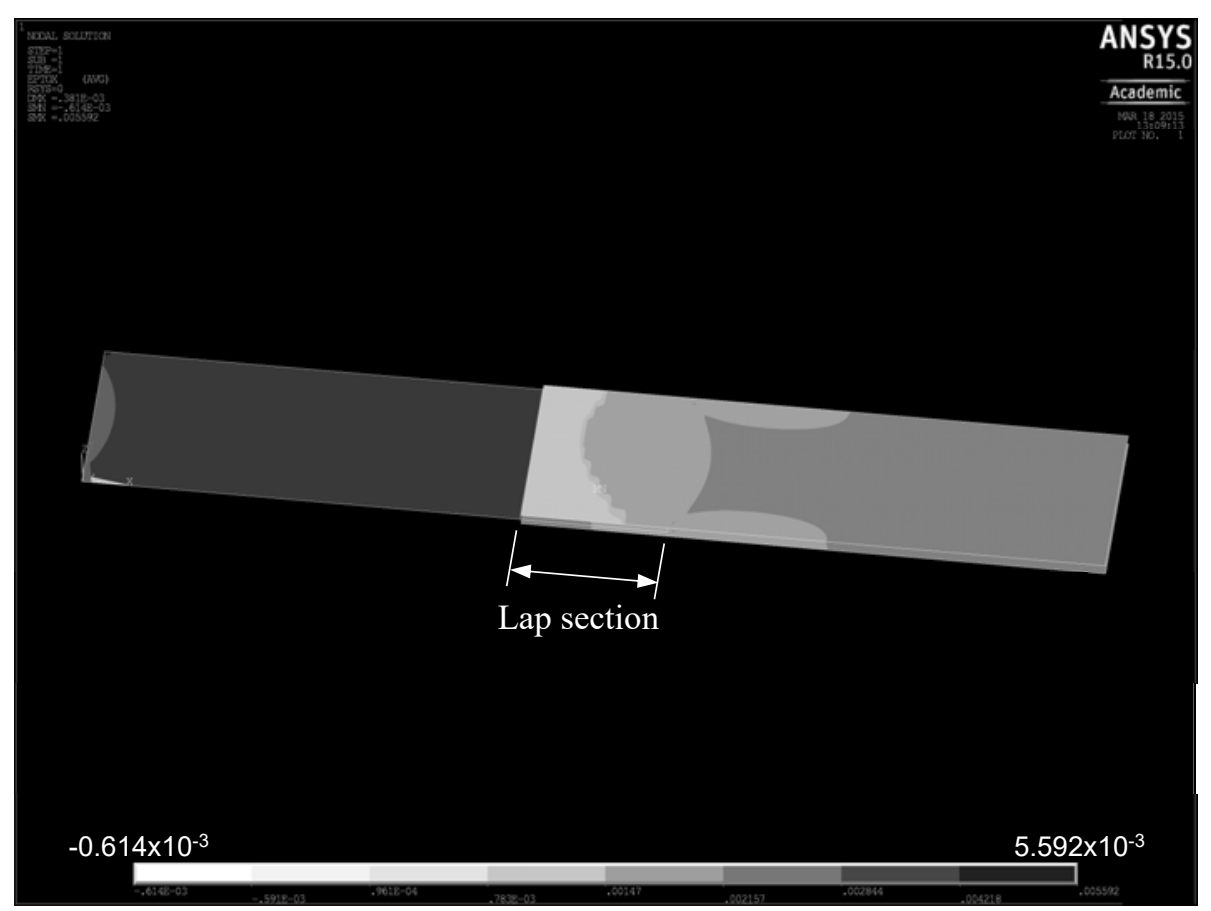

(a) $N=2000$

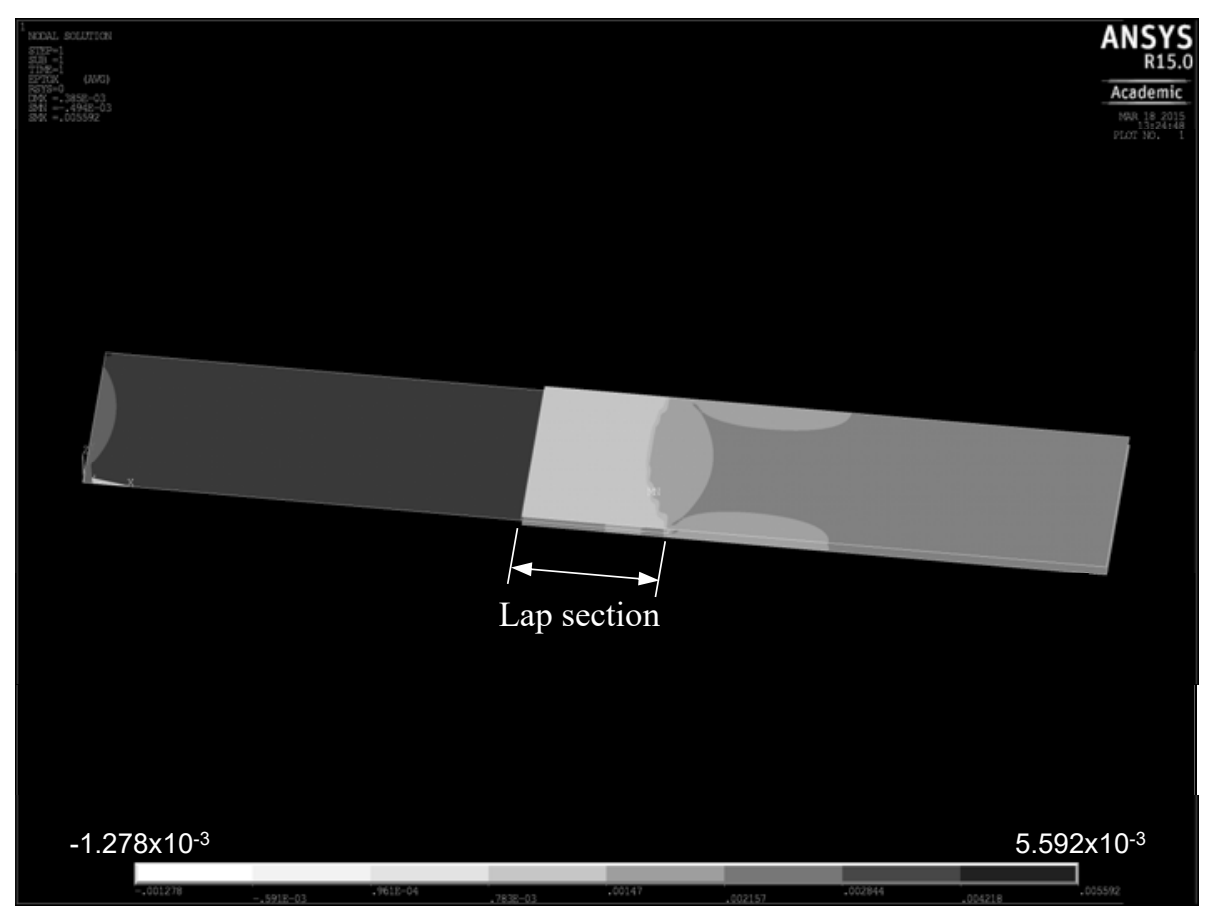

(b) $N=8000$

Figure 8 
(a) FBG \#1

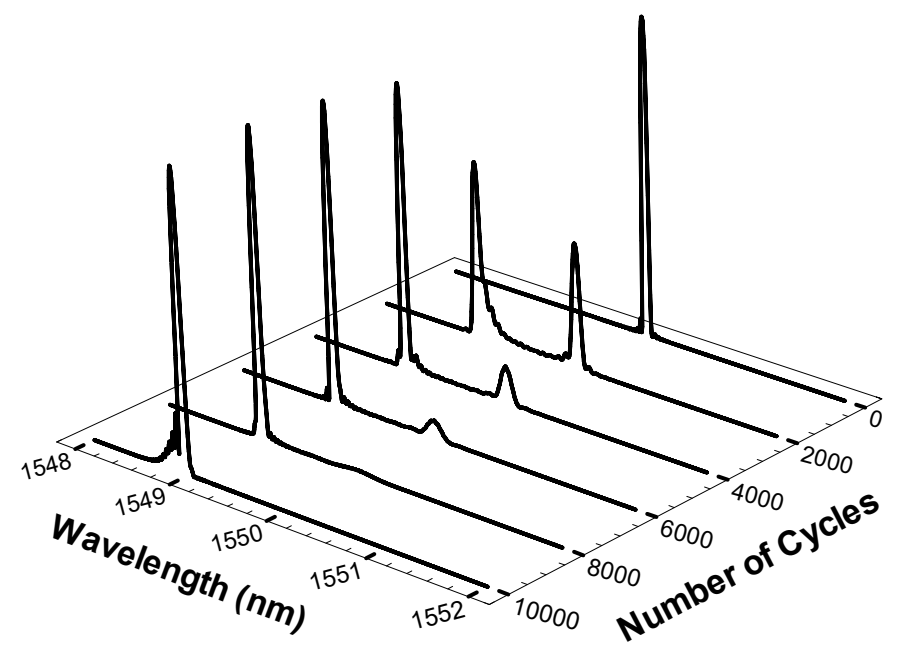

(b) FBG \#2

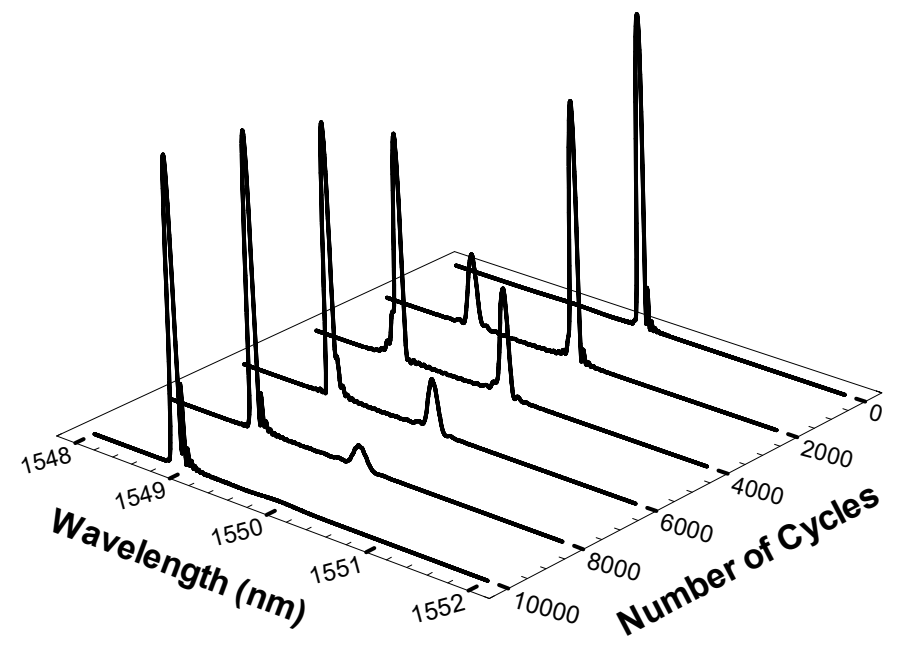

(c) FBG \#3

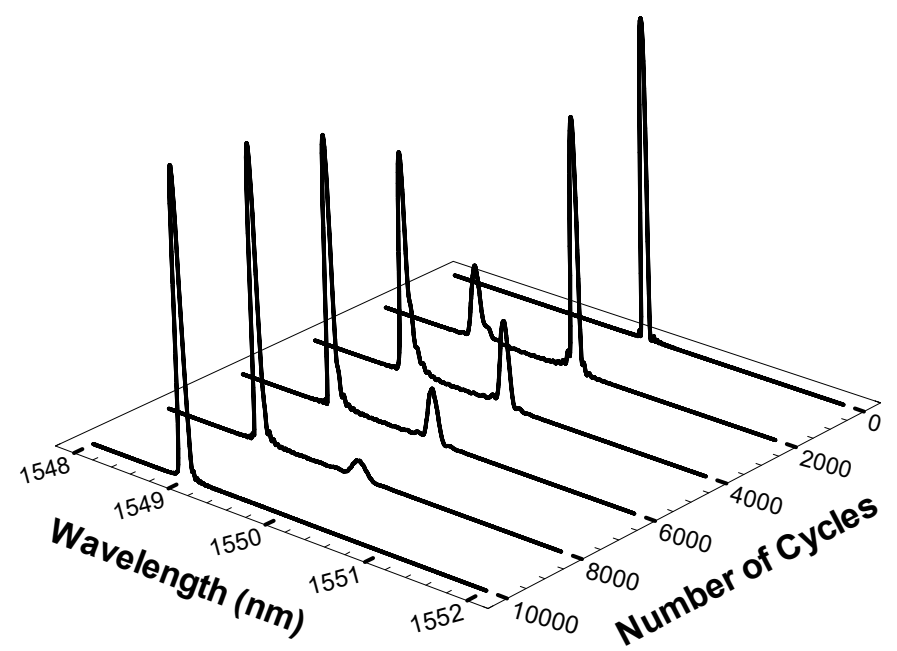

Figure 9 


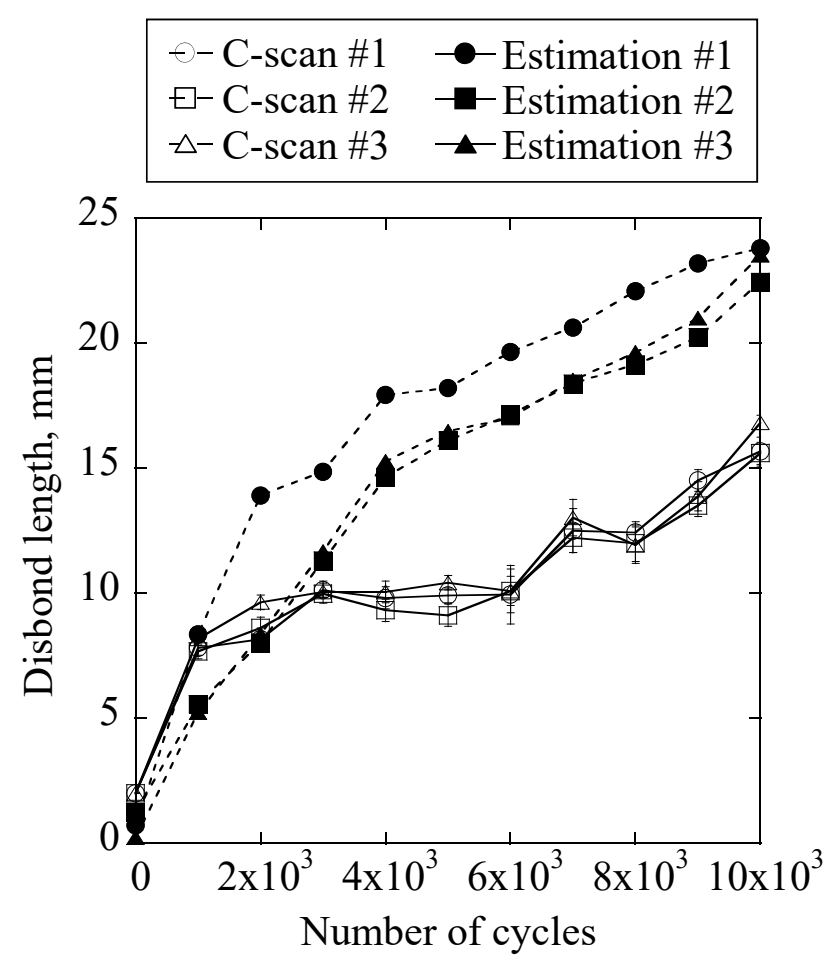

Figure 10 


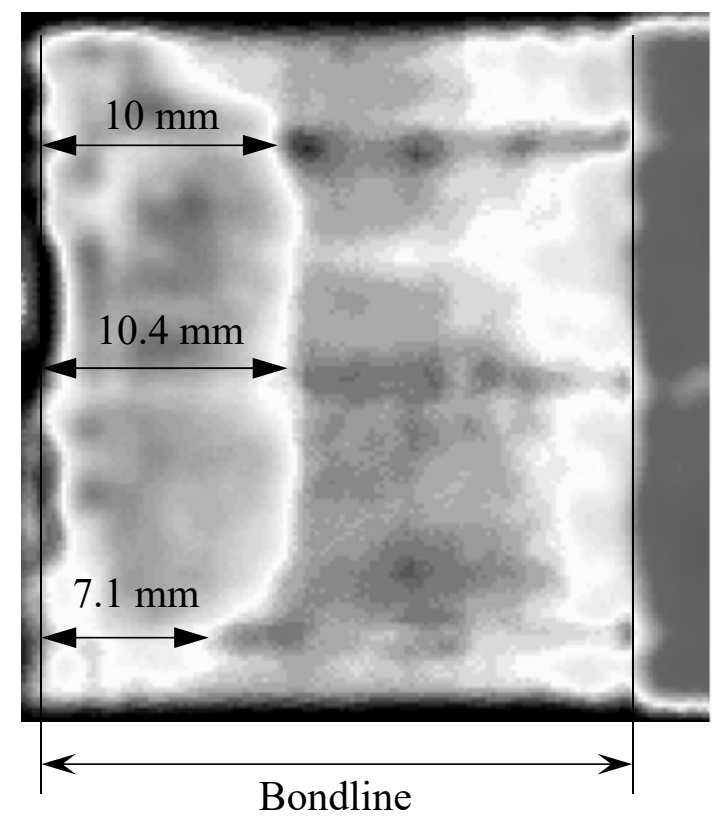

(a) Ultrasonic C-scan image

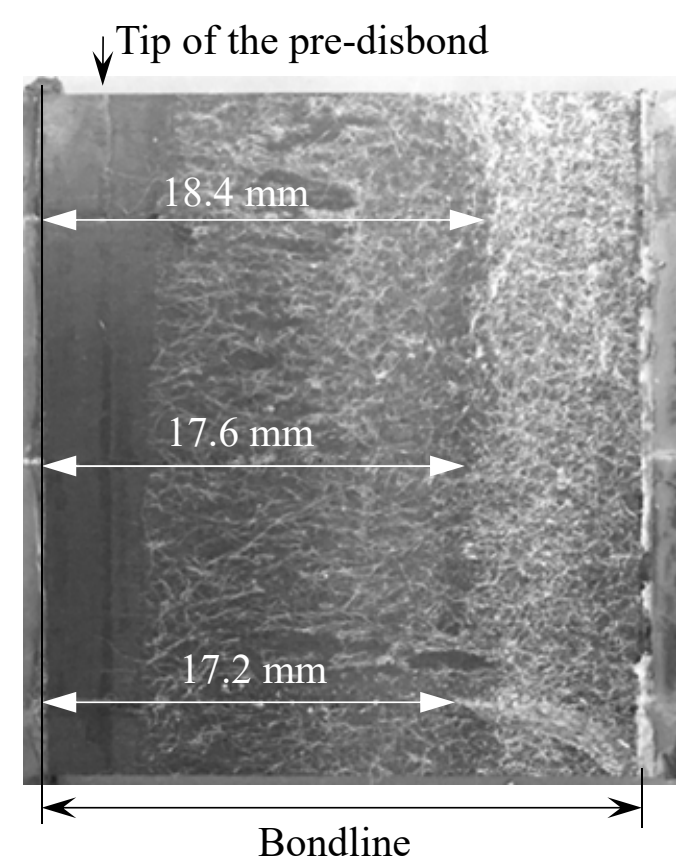

(c) Microphotograph

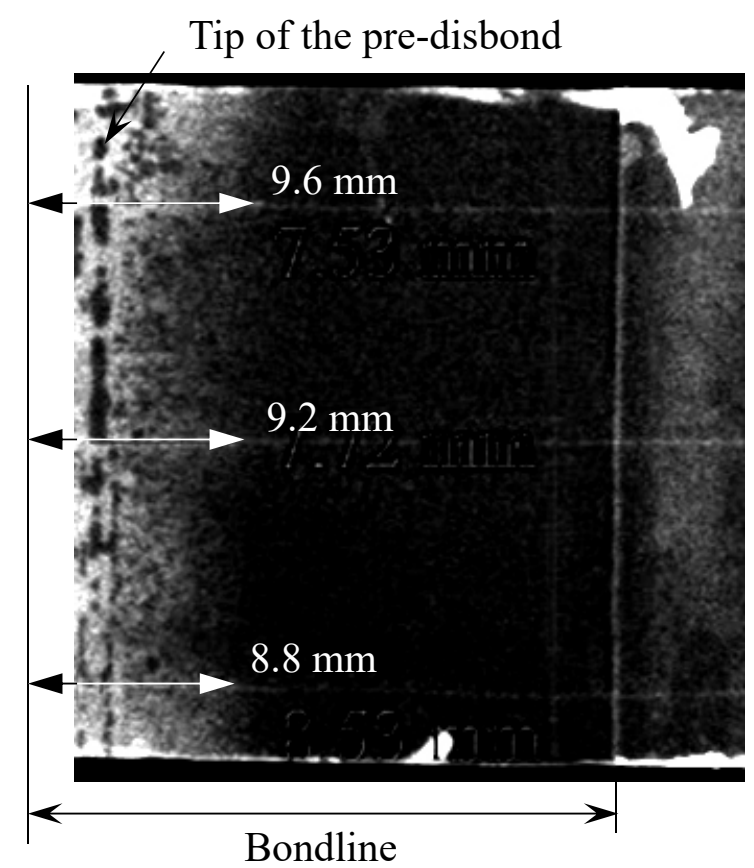

(b) Soft X-ray photograph 


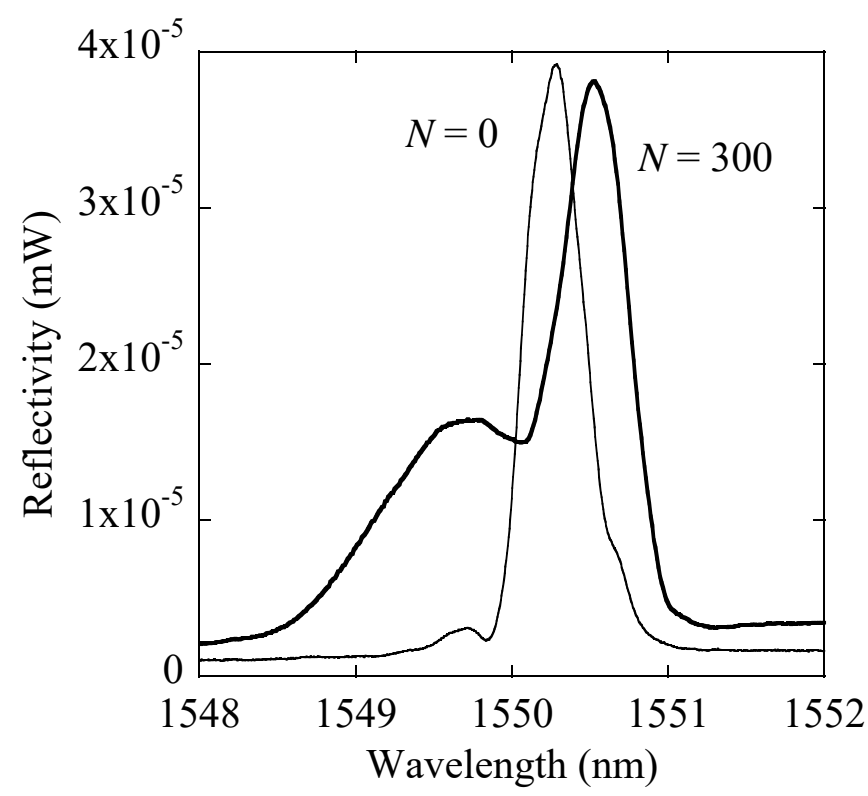

(a) Reflection spectrum

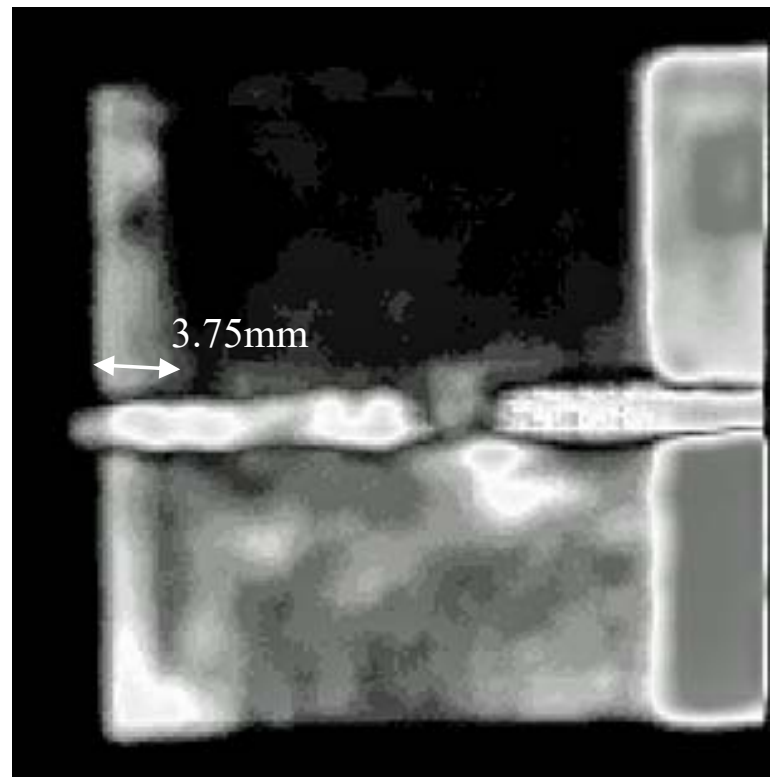

(b) Ultrasonic C-scan image

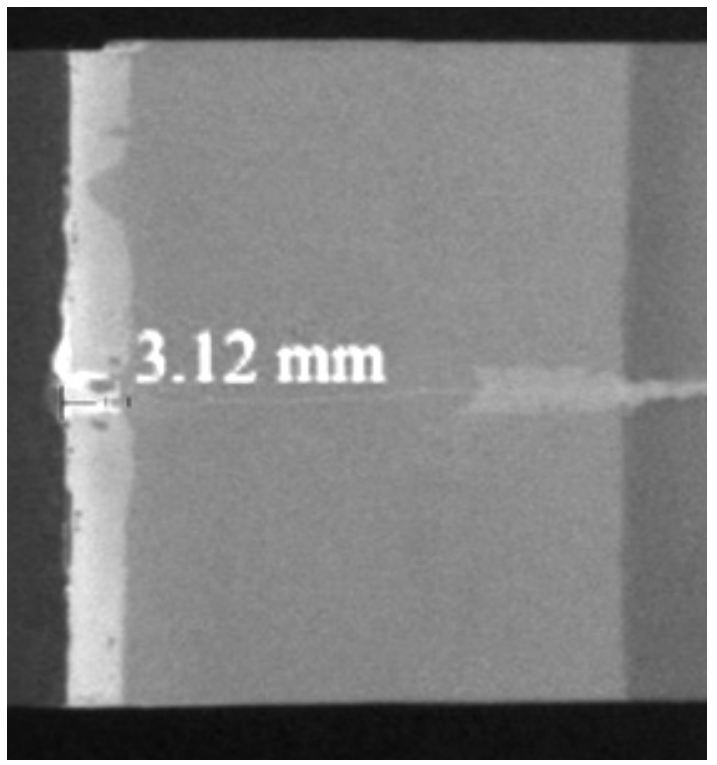

Figure 12

(c) Soft X-ray photograph 